\title{
A scalar damage model with a shear retention factor for the analysis of reinforced concrete structures: theory and validation
}

\author{
Roberto Scotta $^{a}$, Renato Vitaliani $^{a}$, Anna Saetta ${ }^{b}$, Eugenio Oñate ${ }^{c, *}$, \\ Alex Hanganu ${ }^{c}$ \\ a Dipartimento di Costruzioni e Trasporti, Università di Padova, Padova, Italy \\ b Dipartimento di Costruzione dell'Architettura, Istituto Universitario di Architettura di Venezia, Venezia, Italy \\ ${ }^{\mathrm{c}}$ Universitat Politecnica de Cataluña, E.T.S Ingenieros de Caminos, Canales y Puertos, Gran Capitan, s/n, 08034 Barcelona, Spain
}

Received 19 October 1999; accepted 15 July 2000

\begin{abstract}
A local isotropic single parameter scalar model that can simulate the mechanical behaviour of quasi-brittle materials, such as concrete, is described. The constitutive law needs the mechanical characteristics and the fracture energy of concrete to be completely defined. The damage parameter is obtained directly from the value of an equivalent effective stress in order to reduce the computing effort. Due to the unique damage parameter, this model is suitable for the study of quasi-static problems involving monotonically increasing loads. The problem of localisation and mesh dependency have been partially overcome by using an enhanced local method in which a characteristic internal length related to the mesh dimension is employed instead of the characteristic fracture length. In this work, the model was enriched further with the introduction of a shear retention factor that accounts for the friction between the two surfaces of a crack. These new features assure a real improvement of the damage model, maintaining nevertheless its simplicity and low computing cost and making it suitable for the practical solution of large scale problems. Several numerical simulations of experimental tests, concerning fracture tests on concrete specimens and beams failing in shear, have been performed for the validation of the model. The main results from the numerical analyses are described and compared with the experimental ones. (c) 2001 Elsevier Science Ltd. All rights reserved.
\end{abstract}

Keywords: Damage; R.C. structures; Shear; Retention factor; Mesh dependency

\section{Introduction}

Continuum damage models are constitutive relations in which the mechanical effect of cracking and void growth is introduced by means of internal state variables, which act on the elastic stiffness of the material. The simplest model was proposed back in the fifties by Kachanov [1] in order to describe the behaviour of al-

\footnotetext{
${ }^{*}$ Corresponding author. Tel.: +34-9-3205-7016; fax: +34-93401-6517.

E-mail address: onate@etseccpb.upc.ed (E. Oñate).
}

loys subjected to creep. These models have become popular for brittle and ductile failure analyses where the effect of damage is represented as a apparent degradation of the Young modulus of the material. In particular, they have been applied to quasi-brittle materials such as concrete.

In this work, an isotropic, single parameter damage model based on the theory of Kachanov [1] and on the contributions by Simo and Ju [2], Lubliner et al. [3] and Oliver et al. [4] has been adopted. It represents the simplest approach to the non-linear analysis of brittle continuum where progressive mechanical degradation due to the applied action has to be considered. 
To overcome the problem of localisation and mesh dependency, that typically arises in mechanical analyses of strain softening materials, in this paper an enriched local method is employed in which a characteristic internal length, related to the mesh dimension, substitutes the characteristic fracture length. Such a method, which is actually a mesh size regularized method, has been used in Ref. [5], and named enhanced local method (e.1.m.). It is a simplified approach, which conjugates a low computational cost with a sufficient reliability of the results. In particular by means of the proposed approach the energy dissipated in a band of cracking elements does not depend on the width of the band. Several tests $[5,6]$ demonstrated that with this method, even if the mesh dependency in term of width of the band is not controlled, the reliability of the results in term of global response, e.g. load-displacement curve is assured. The validation of the e.l.m. is given by the numerical simulation of the experimental procedures for fracture energy measures of cement paste on parallelepiped notched specimens.

The main original contribution of this work consists in the improvement of the damage model by the intro-

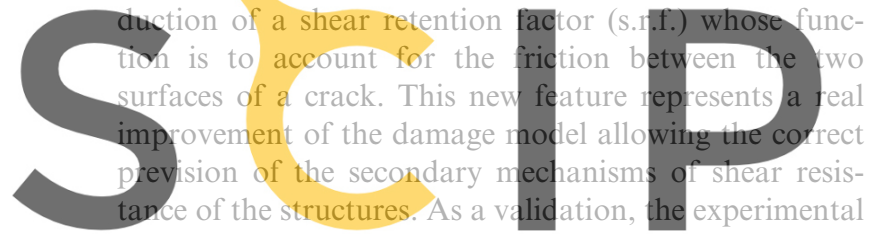
test of a four point bending of a reinforced concrete beam without shear reinforcement, failing in shear [7],

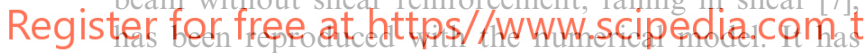
been observed that the model without the shear retention factor, or with a constant factor, was not able to predict the measured failure load. Only the use of a variable shear retention factor has allowed for a good fitting between numerical and experimental results. The s.r.f. evolution law, which is given in the paper, has been calibrated on the basis of the available laboratory tests.

The effectiveness of the proposed theory has been proved through several numerical simulations of experimental tests, concerning beams failing in bending and in shear [8] and the numerical reproduction of the "shear valley" obtained by Kani [9]. The main results from these analyses are described and compared with the experimental ones in the following.

Previous works, [10-14] have shown that, despite its simplicity, the single parameter damage model used in this work, represents a well-balanced compromise between the need for an accurate description of the mechanical behaviour of concrete and the requirement of small computational effort, necessary when facing large scale problems. The introduced new features, i.e. the enhanced local method and the shear retention factor, do not compromise the simplicity and low computing cost of the damage model thus making it suitable for the practical solution of large scale problems.

\section{The damage model}

\subsection{Energetic considerations}

In Section 2.2, a strain-space damage model, based on the notion of effective stress, as fully explained in Ref. [2], is adopted. It will be applied to the study of small displacements and small strain problems. In a steadystate thermal condition, the specific free elastic energy at a point of a damaged material can be defined as

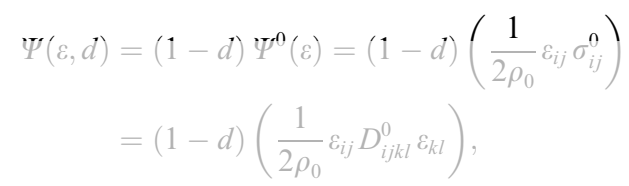

where $d$ (ranging from 0 to 1 ) is a scalar value representing the local damage parameter, $\rho_{0}$ is the material specific mass, $\varepsilon_{i j}$ and $\sigma_{i j}^{0}$ are, respectively, the strain and the effective stress tensors and $D_{i j k l}^{0}$ is the fourth-order

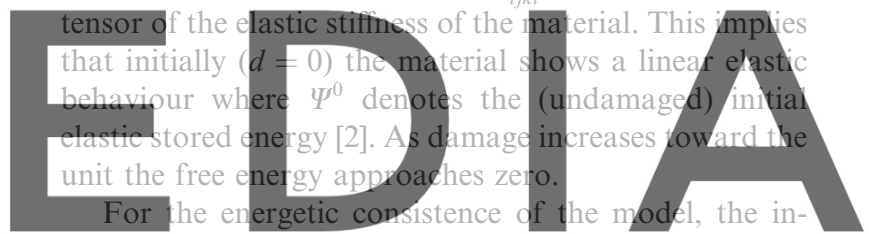

equality of Clausius-Planck, that states the no-negative character of the rate of mechanical energy dissipation down Rad the versigniwatholitithe watermark equilibrium condition, has to be assured

$\dot{\Xi}_{m}=\frac{1}{\rho_{0}} \sigma_{i j} \dot{\varepsilon}_{i j}-\dot{\Psi} \geqslant 0$,

where $\sigma_{i j}$ is the stress tensor. Eq. (2) can be written as

$$
\begin{aligned}
\dot{\Xi}_{m} & =\frac{1}{\rho_{0}} \sigma_{i j} \dot{\varepsilon}_{i j}-\left(\frac{\partial \Psi}{\partial \varepsilon_{i j}} \dot{\varepsilon}_{i j}+\frac{\partial \Psi}{\partial d} \dot{d}\right) \\
& =\left(\frac{1}{\rho_{0}} \sigma_{i j}-\frac{\partial \Psi}{\partial \varepsilon_{i j}}\right) \dot{\varepsilon}_{i j}-\frac{\partial \Psi}{\partial d} \dot{d} \geqslant 0 .
\end{aligned}
$$

Since the variation $\dot{\varepsilon}_{i j}$ is completely arbitrary, this inequality can be fulfilled only if the term in parentheses is identically null:

$\frac{1}{\rho_{0}} \sigma_{i j}-\frac{\partial \Psi}{\partial \varepsilon_{i j}}=0$

from which one obtains

$\sigma_{i j}=\rho_{0} \frac{\partial \Psi}{\partial \varepsilon_{i j}}=(1-d) D_{i j k l}^{0} \varepsilon_{k l}=D_{i j k l}^{\mathrm{S}} \varepsilon_{k l}$,

where $D_{i j k l}^{\mathrm{S}}$ represents the secant stiffness matrix of the material. Eq. (3) can be simplified into

$\dot{\Xi}=-\frac{\partial \Psi}{\partial d} \dot{d}=\Psi^{0} \dot{d} \geqslant 0$ 
that is always satisfied if $d$ is a non-decreasing variable (i.e. $\dot{d} \geqslant 0$ ), $\Psi^{0}$ being positive definite.

\subsection{Limit damage surface}

According to the strain-space damage model developed by Simo and Ju [2], at a generic point of the material the damage criterion can be written by using strain as variable, or alternatively elastic stresses, i.e. effective stresses, as follows:

$F\left(\sigma_{i j}^{0}, \tau\right)=\bar{\sigma}\left(\sigma_{i j}^{0}\right)-\tau \leqslant 0$

where $\bar{\sigma}\left(\sigma_{i j}^{0}\right)$, named equivalent effective stress, is a scalar function of the undamaged stress tensor $\sigma_{i j}^{0}$ and $\tau$ is a material parameter that keeps memory of the load history. The condition $F\left(\sigma_{i j}^{0}, \tau\right)=0$ defines the damage surface.

Theoretically, any form of the function $F$ can be assumed; however, in order to be convenient in terms of formal simplicity and saving of computation time, $F$ should be a homogeneous linear function of stresses (e.g. the criterion of Mohr-Coulomb, Druker-Prager and

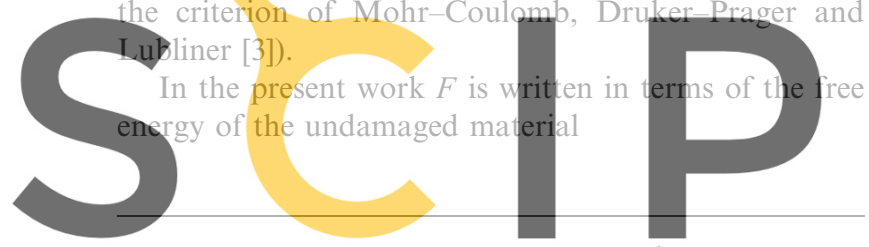

\section{E}

$F=\frac{[1+r(n-1)]}{n} \sqrt{2 \rho_{0} \Psi^{0}}-\tau \leqslant 0$

where $n=f_{\mathrm{c}} / f_{\mathrm{t}}$ with $f_{\mathrm{c}}$ and $f_{\mathrm{t}}$ the compressive and tensile strength of concrete and

$r= \begin{cases}0 & \text { if } \sum_{i=1}^{3}\left|s_{i i}^{0}\right|=0 \\ \frac{\sum_{i=1}^{3}\left\langle s_{i i}^{0}\right\rangle}{\sum_{i=1}^{3}\left|s_{i i}^{0}\right|} & \text { if } \sum_{i=1}^{3}\left|s_{i i}^{0}\right|>0 \quad \text { where }\langle x\rangle=\frac{1}{2}(|x|+x),\end{cases}$

where $s_{i j}^{0}$ denotes the tensor of the effective principal stresses.

The relationship (8) of the damage field has been proposed and used previously by Oñate et al. [15]. It gives the shape of the limit damage surface whose intersection with planes corresponding to different values of the third principal stress $s_{33}^{0}$ is shown in Fig. 1. In this work, the following modification of Eq. (8) has been adopted [6]:

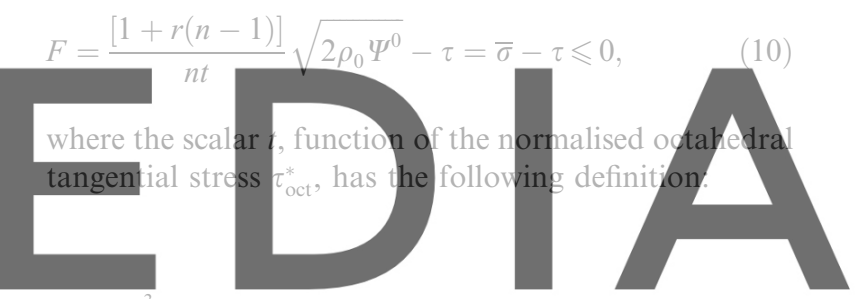

if $\sum^{3}\left\langle-s_{j i}^{0}\right\rangle>0$.

Register for free at https//www.scipedia.com to download the version without the watermark $t=0.975+a \exp \left(\frac{\mathrm{oct}}{b}\right)$ with $\tau_{\mathrm{oct}}^{*}=$ $\left\{\sqrt{i=1}^{\frac{1}{3} \sum_{i=1}^{3}}\left(\frac{\left\langle-s_{i i}^{0}\right\rangle}{\sum_{j=1}^{3}\left\langle-s_{j j}^{0}\right\rangle}-\frac{1}{3}\right) \quad\right.$ otherwise

(a)

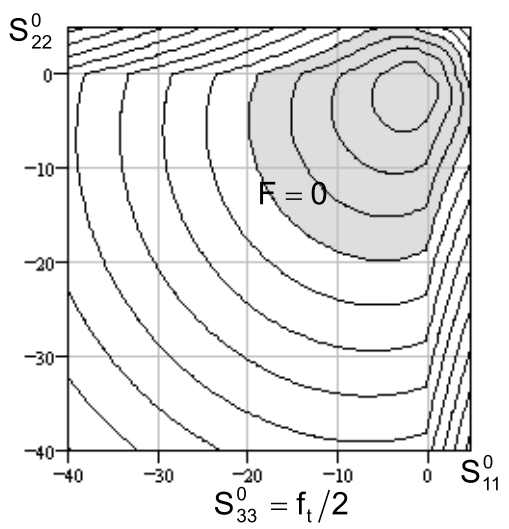

(b)

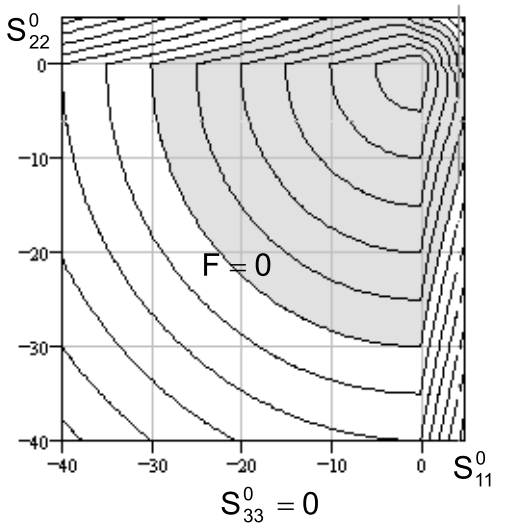

(c)

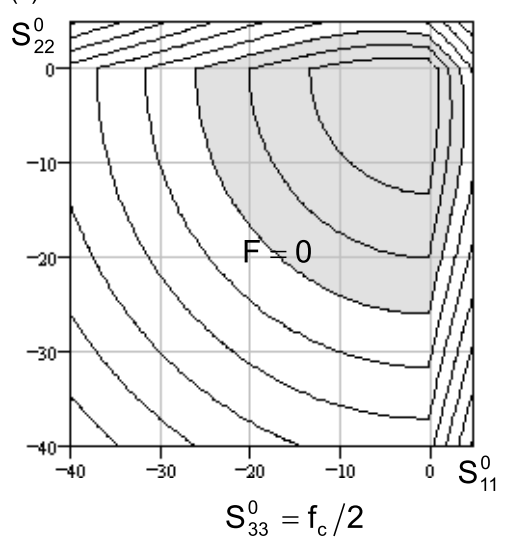

Fig. 1. Original limit damage surface as in Ref. [14]. Intersection with the planes: (a) $s_{33}=f_{\mathrm{t}} / 2$, (b) $s_{33}=0$ and (c) $s_{33}=f_{\mathrm{c}} / 2$. Test with $f_{\mathrm{c}}=30 \mathrm{MPa}$ and $f_{\mathrm{t}}=3 \mathrm{MPa}$. 
and allows one to consider the strength increase that concrete, exhibits in biaxial or three-axial compressive state. Assuming the parameters $a=16.347$ and $b=$ 0.07269 , the intersections of the resulting modified admissible field with the $s_{33}^{0}=0$ plane and the octahedral plane $s_{33}^{0}=\left(s_{11}^{0}+s_{22}^{0}\right) / 2$ are plotted in Fig. 2. It can be seen that in triaxial hydrostatic compressive state the limit field reaches a value that is 10 times the uniaxial value $f_{\mathrm{c}}$. Note that the parameter $t$ is equal to 1 if one or no compressive principal stress is present $\left(\tau_{\text {oct }}^{*}=\sqrt{2} / 3\right)$, while in the presence of triaxial hydrostatic compressive state $\tau_{\text {oct }}^{*}=0$ and $t$ is equal to $0.975+a$. Different choices of the parameters $a$ and $b$ in Eq. (11) are possible.

\subsection{Damage evolution}

A fully equivalent expression for Eq. (10), more convenient for the following derivation, is

$F=G(\bar{\sigma})-G(\tau) \leqslant 0$

with $G($ ) a suitable monotonic scalar function. Consequently, the evolution law of damage can be expressed
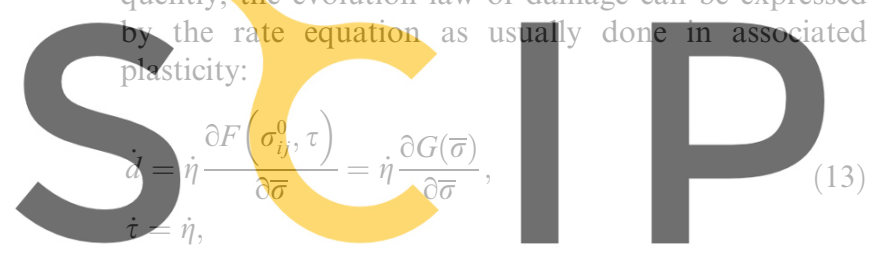

with the Kuhn-Tucher conditions $\dot{\eta} \geqslant 0, F \leqslant 0$ and plastic multiplier in rate independent plasticity. The Kuhn-Tucker conditions state that

(i) the rate of damage growth is positive or zero $(\dot{\eta} \geqslant 0)$,

(ii) strain and stress states located outside the elastic domain defined by Eq. (10) are not allowed $(F \leqslant 0)$, (iii) when damage grows the loading function remains equal to zero $(\dot{\eta} F=0)$.

The combination of these three conditions yields the consistency condition $\dot{F}=0$, which has to be satisfied whenever there is a growth of damage. If $F=0$ and $\dot{F}=0$, then from Eq. (12) one derives $\tau=\bar{\sigma}$ and from Eq. (13), $\dot{d} \geqslant 0$, else $\dot{d}=0$ and $\dot{\tau}=0$.

Initially, there must be $\tau=f_{\mathrm{t}}$ since the uniaxial tensile strength of concrete is the threshold of the equivalent stress for the onset of damage.

Of particular numerical convenience is the choice of a direct explicit function for $d$. The following, proposed by Oliver [4], has been adopted in this work:

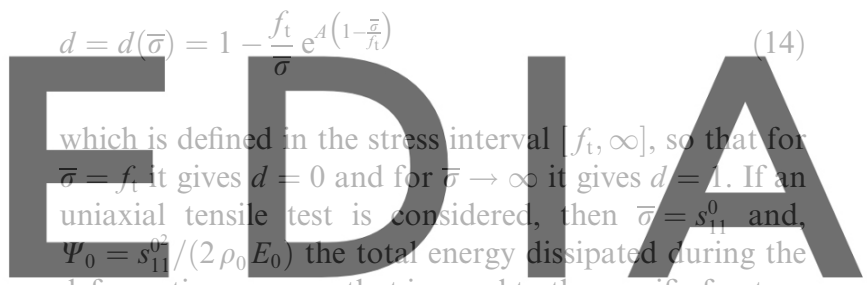
deformation process, that is equal to the specific fracture energy of the material $g_{\mathrm{f}}[16]$, can be obtained by the dobviahoad the versiong Withouts thie byatermark (a)

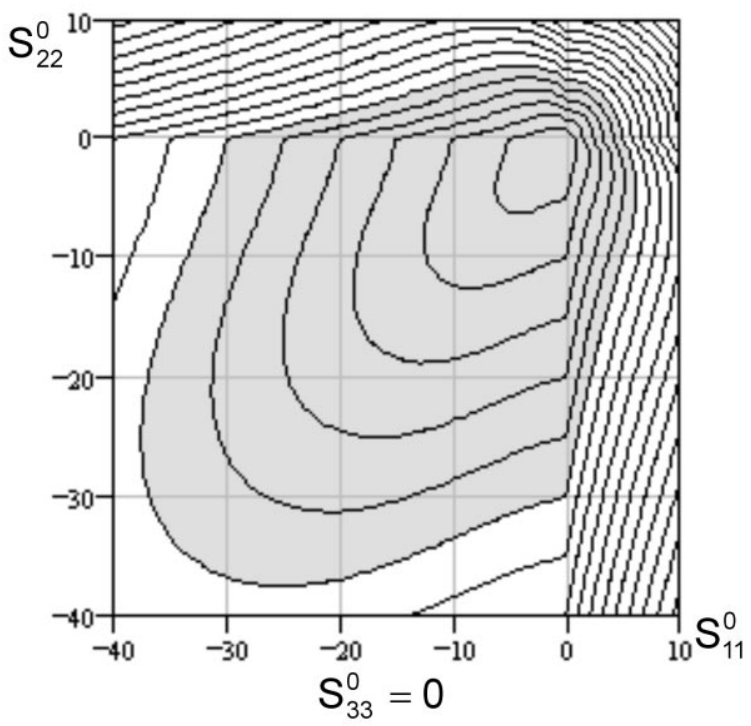

(b)

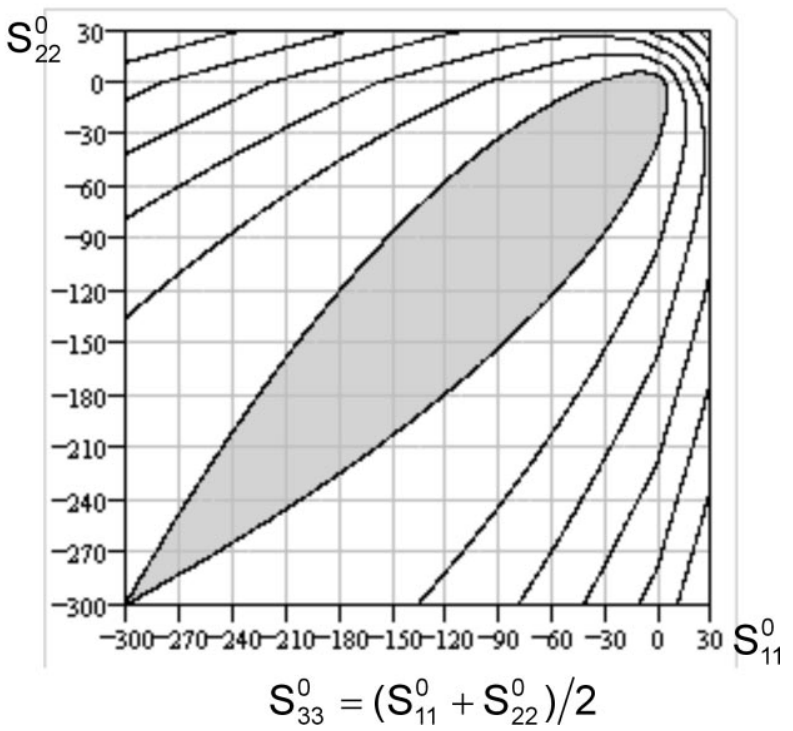

Fig. 2. Limit damage surface adopted in this work. Intersection with the planes: (a) $s_{33}=0$ and (b) $s_{33}=\left(s_{11}+s_{22}\right) / 2$. Test with $f_{\mathrm{c}}=30 \mathrm{MPa}$ and $f_{\mathrm{t}}=3 \mathrm{MPa}$. 
$g_{\mathrm{f}}=\int_{f_{\mathrm{t}}}^{\infty} \Psi_{0} \mathrm{~d}(d)=\int_{f_{\mathrm{t}}}^{\infty} \frac{s_{11}^{0^{2}}}{2 \rho_{0} E_{0}} \frac{\mathrm{d}(d)}{\mathrm{d} s_{11}^{0}} \mathrm{~d} s_{11}^{0}$.

After some mathematics, the following result is obtained:

$g_{\mathrm{f}}=\frac{f_{\mathrm{t}}^{2}}{\rho_{0} E_{0}}\left[\frac{1}{2}+\frac{1}{A}\right] \Rightarrow A=\left(\frac{g_{\mathrm{f}} \rho_{0} E_{0}}{f_{\mathrm{t}}^{2}}-\frac{1}{2}\right)^{-1}$.

This relationship shows that the parameter $A$ in Eq. (14) depends on the specific fracture energy dissipated during the whole damaging process. The total dissipated energy must be greater than the elastic free energy of the undamaged material stored at the onset of damage:

$g_{\mathrm{f}}=\bar{\Psi}_{0}^{*}+\Delta \Xi=\frac{f_{\mathrm{t}}^{2}}{2 \rho_{0} E_{0}}+\Delta \Xi \quad$ with $\Delta \Xi \geqslant 0$.

When introduced in Eq. (16), this gives

$A=\frac{f_{\mathrm{t}}^{2}}{\Delta \Xi \rho_{0} E_{0}}=\frac{2 \bar{\Psi}_{0}^{*}}{\Delta \Xi}$

which puts into evidence the non-negative character of parameter $A$.

Analogously a uniaxial compression test can be considered and the symbol $\Xi_{\mathrm{c}}$ is adopted to identify the global energy dissipation. Since te describe both the compressi haviour of the material, the ween $g_{\mathrm{f}}$ and $\Xi_{\mathrm{c}}$ holds: $A=\left(\frac{\Xi_{\mathrm{c}} \rho_{0} E_{0}}{f^{2}}-\frac{1}{2}\right)^{-1} \Rightarrow \Xi_{\mathrm{c}}=n^{2} g_{\mathrm{f}}$.

Register for free at https//www.scipedia.com to The density of fracture energy $g_{\mathrm{f}}\left(\right.$ or $\Xi_{\mathrm{c}}$ ) is a characteristic of the material, as the other mechanical parameters $E_{0}, v, f_{\mathrm{t}}$ and $f_{\mathrm{c}}$ and it is defined as the fracture energy normalised to the characteristic length of fracture: $g_{\mathrm{f}}=G_{\mathrm{f}} / l_{\mathrm{c}}$. The value of the fracture energy $G_{\mathrm{f}}$ can be measured by means of a bending test on parallelepiped specimens [16]. More details on the value of $l_{\mathrm{c}}$ will be given in this work when the problem of the localisation in strain-softening analyses is addressed.

\subsection{Tangential constitutive law for the damaged material}

The constitutive relationship (5) can be rewritten in an incremental form as follows [13]:

$\delta \boldsymbol{\sigma}=\mathbf{D}^{\mathrm{S}} \delta \boldsymbol{\varepsilon}+\delta \mathbf{D}^{\mathrm{S}} \boldsymbol{\varepsilon}=(1-d) \mathbf{D}^{0} \delta \boldsymbol{\varepsilon}-\mathbf{D}^{0} \delta \mathrm{d} \boldsymbol{\varepsilon}$,

where matrix notation has been adopted. Eq. (20), after substitution of Eq. (13) for $\delta d$, becomes

$$
\begin{aligned}
\delta \boldsymbol{\sigma} & =(1-d) \mathbf{D}^{0} \delta \boldsymbol{\varepsilon}-\mathbf{D}^{0} \boldsymbol{\varepsilon} \dot{\tau} \frac{\partial G}{\partial \bar{\sigma}} \delta \bar{\sigma} \\
& =(1-d) \mathbf{D}^{0} \delta \boldsymbol{\varepsilon}-\boldsymbol{\sigma}^{0} \dot{\tau} \frac{\partial G}{\partial \bar{\sigma}} \frac{\partial \bar{\sigma}}{\partial \boldsymbol{\sigma}^{0}} \mathbf{D}^{0} \delta \boldsymbol{\varepsilon}
\end{aligned}
$$

and finally rewrites as $\delta \boldsymbol{\sigma}=\left[(1-d) \mathbf{I}-\boldsymbol{\sigma}^{0} \dot{\tau} \frac{\partial G}{\partial \bar{\sigma}} \frac{\partial \bar{\sigma}}{\partial \boldsymbol{\sigma}^{0}}\right] \mathbf{D}^{0} \delta \boldsymbol{\varepsilon}=\mathbf{D}^{\mathrm{T}} \delta \boldsymbol{\varepsilon}$,

where the non-symmetric tangent stiffness matrix $\mathbf{D}^{\mathrm{T}}$ depends only on the vector of the effective stress $\sigma^{0}$.

In this paper, the modified Newton-Raphson schemes, where the secant stiffness matrix (5) or the initial stiffness matrix are used in place of the nonsymmetric tensor $\mathbf{D}^{\mathrm{T}}$, have been preferred in numerical applications since they require less computational effort and assure stability to the numerical solution.

2.5. Strain softening behavior and regularization technique for the damage approach

As known, the standard local constitutive laws are inappropriate to model strain softening material behaviour. Indeed, when the tangent stiffness matrix ceases to be positive definite, the finite element analysis shows strong spurious mesh sensitivity, becoming nonobjective [17]. The mesh dependency manifests itself in terms of shape and dimension of the damaged zone (the strain localises into a narrow band, whose width de-

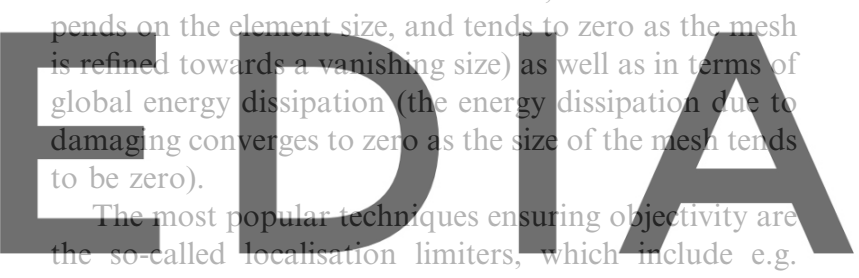

gradient models [18] and non-local models.

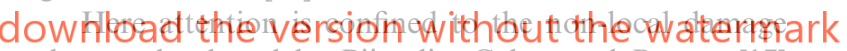

theory, developed by Pijaudier-Cabot and Bazant [17] and Bazant [19], whose localisation properties were extensively studied by Pijaudier-Cabot and Benallal [20].

In the non-local approach to the proposed damage model, the non-local equivalent tensile stress $\tilde{\sigma}$ is introduced in Eq. (14) to replace the corresponding local value $\bar{\sigma}$, to control the growth of damage index $d$. Such a non local variable $\tilde{\sigma}$ represents the average of the local equivalent effective stress $\bar{\sigma}$ over the representative spherical volume surrounding each point of the material,

$\tilde{\sigma}=\frac{1}{V_{\mathrm{r}}(x)} \cdot \int_{V} \psi(x-s) \cdot \bar{\sigma} \cdot \mathrm{d} s \quad$ with

$V_{\mathrm{r}}(x)=\int_{V} \psi(x-s) \mathrm{d} s$,

where $V$ is the volume of the structure, $V_{\mathrm{r}}(x)$ is the representative volume of material at point $x$ and $\psi(x-s)$ is a selected weight function, usually

$\psi(x-s)=\exp \left(-\frac{\|x-s\|^{2}}{2 l_{\mathrm{c}}^{2}}\right)$.

The internal length $l_{\mathrm{c}}$ helps to limit the localisation process and control the size of the localisation zone. For standard concrete, Bazant and Pijaudier-Cabot [21] 
demonstrated that $l_{\mathrm{c}}$ is equivalent to the characteristic internal length of fracture given by

$l_{\mathrm{c}}=\frac{G_{\mathrm{f}}}{g_{\mathrm{f}}} \cong 3.0 d_{\mathrm{a}}$,

where $G_{\mathrm{f}}$ is the fracture energy $\left(\mathrm{J} / \mathrm{m}^{2}\right)$ and $g_{\mathrm{f}}$ is the specific fracture energy $\left(\mathrm{J} / \mathrm{m}^{3}\right)$ that can be experimentally measured in bending tests on notched concrete specimens. Typically, $l_{c}$ depends on the maximum size of aggregates $d_{\mathrm{a}}$ as written in Eq. (25).

Provided the mesh refinement is adequate, with a non local approach the size and shape of the damaged zone become independent of the mesh size, type and orientation, and the solution properly converges toward a mesh independent unique solution [20].

However, the benefits derived from the use of a nonlocal approach are balanced by some drawbacks. First of all, in the absence of an adaptive mesh refinement, which is still a research issue for localisation, for the non-localisation process to be efficient, it is necessary to adopt a uniform mesh discretisation with the maximum size of the elements of about $1 / 2 \mathrm{~cm}$ (i.e. a sufficient number of Gauss points used for the numerical integration in the finite element (FE) analysis have to be

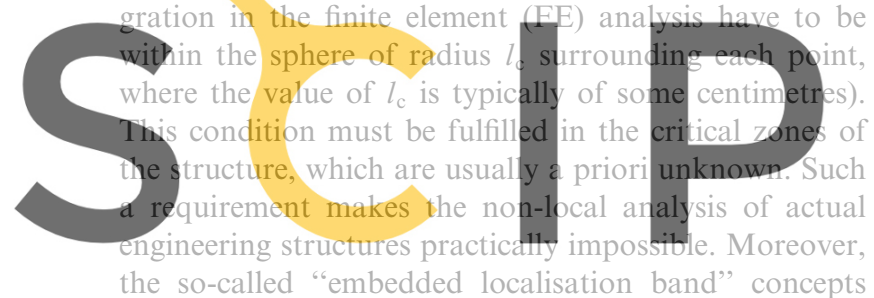

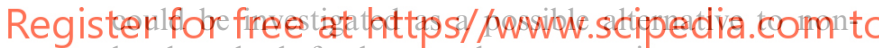
local methods for large scale computations.

A second obstacle to the applicability of the non-local analysis is the sensible increase of the computational time that the process of non-localisation of the variables requires. In practice, at each iteration imposed by the solution algorithm of the non-linear problem, once the local value $\bar{\sigma}$ is evaluated at each Gauss point of the mesh, the corresponding non-local $\tilde{\sigma}$ value must be calculated before the damage parameter at the same Gauss point can be updated. This operation consists in multiplication of vectors of local values by the non-symmetric weighting matrix following from Eq. (23). Finally, the analysis becomes heavier if a full Newton-Raphson algorithm is adopted for the solution of the non-linear algebraic system, since the non-local approach increases the non-symmetry of the tangent stiffness matrix, which is already non-symmetric as Eq. (22) shows.

Due to the above exposed argumentation, a simplified approach, named (e.l.m.), alternative to the nonlocal theory, has been used in this work. It consists in the modification of Eq. (16) as follows:

$A^{(\mathrm{e})}=\left(\frac{G_{\mathrm{f}} \rho_{0} E_{0}}{l_{\mathrm{c}}^{(\mathrm{e})} f_{\mathrm{t}}^{2}}-\frac{1}{2}\right)^{-1}$, where the characteristic length $l_{\mathrm{c}}^{(\mathrm{e})}$, and therefore the parameter $A^{(\mathrm{e})}$, are dependent on the size of every finite element used in the FE mesh. The length $l_{\mathrm{c}}^{(\mathrm{e})}$ counterbalances the lack of the characteristic length as independent variable, typical of all the local continuum models, even the ones based on fracture mechanics concepts.

The concept of making the local model dependent on the FE size has been suggested, for example, by Refs. [23-25], and applied by many authors, e.g. Ref. [26]. Oliver [22] proposed the following relationship for the characteristic length $l_{\mathrm{c}}^{(\mathrm{e})}$ :

$l_{\mathrm{c}}^{(\mathrm{e})}=\frac{V^{(\mathrm{e})}}{\int_{V^{(\mathrm{e})}} \frac{\partial \phi}{\partial x^{\prime}} \mathrm{d} V}$,

where $V^{(e)}$ is the FE volume; $\phi$ is a non-dimensional, continuum and differentiable function defined in the three-dimensional space, which is able to describe the displacements in the localisation band, and $x^{\prime}$ is the linear coordinate, perpendicular to the localisation band. Oliver [22] has demonstrated that a smeared crack analysis application of Eq. (27) leads to a unique mesh

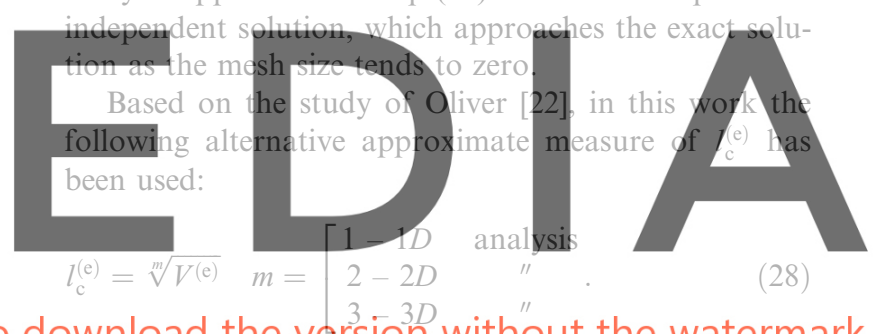

download the version without the watermark

With such an assumption, while fracture energy $G_{\mathrm{f}}$ correctly remains a characteristic of the material, the specific fracture energy $g_{\mathrm{f}}$ becomes dependent on the discretisation and it becomes variable from one element to another.

The effectiveness of this approximate theory can be assessed with the simple test presented in Table 1, where the energy released at cracking is evaluated for three different finite element shapes: it can be observed that the approximate theory gives exactly the analytical value for the cubic element, while for the two irregular elements it gives a solution of the same magnitude of the exact results. On the contrary, the results obtained by using a constant $l_{\mathrm{c}}$ could gives arbitrary values, depending on the selected $l_{\mathrm{c}}$.

Therefore, as the energetic dissipation is concerned, the proposed approximate theory provides a numerical solution that approximates the exact solution, independently of the mesh size, only by using a regular mesh discretisation. In particular it is worth noting that the errors induced by using formulae (28), increases up to infinity with the element slenderness.

Moreover, such an approach does not require the parameter $l_{\mathrm{c}}$ as a known datum of the problem. Indeed 
Table 1

Evaluation of exact and approximate crack energy release for three different finite element shapes

\begin{tabular}{|c|c|c|c|c|c|}
\hline \multirow[t]{3}{*}{ Element shape } & \multirow[t]{3}{*}{ Element volume } & \multirow[t]{3}{*}{ Fracture surface } & \multicolumn{3}{|c|}{ Energy dissipation } \\
\hline & & & \multirow[t]{2}{*}{ Exact } & \multicolumn{2}{|l|}{ FE solution } \\
\hline & & & & $\begin{array}{l}\text { Local model } \\
\left(l_{\mathrm{c}}=\text { constant }\right)\end{array}$ & e.l.m. $l_{\mathrm{c}}^{(\mathrm{e})}=\sqrt[3]{V}$ \\
\hline
\end{tabular}

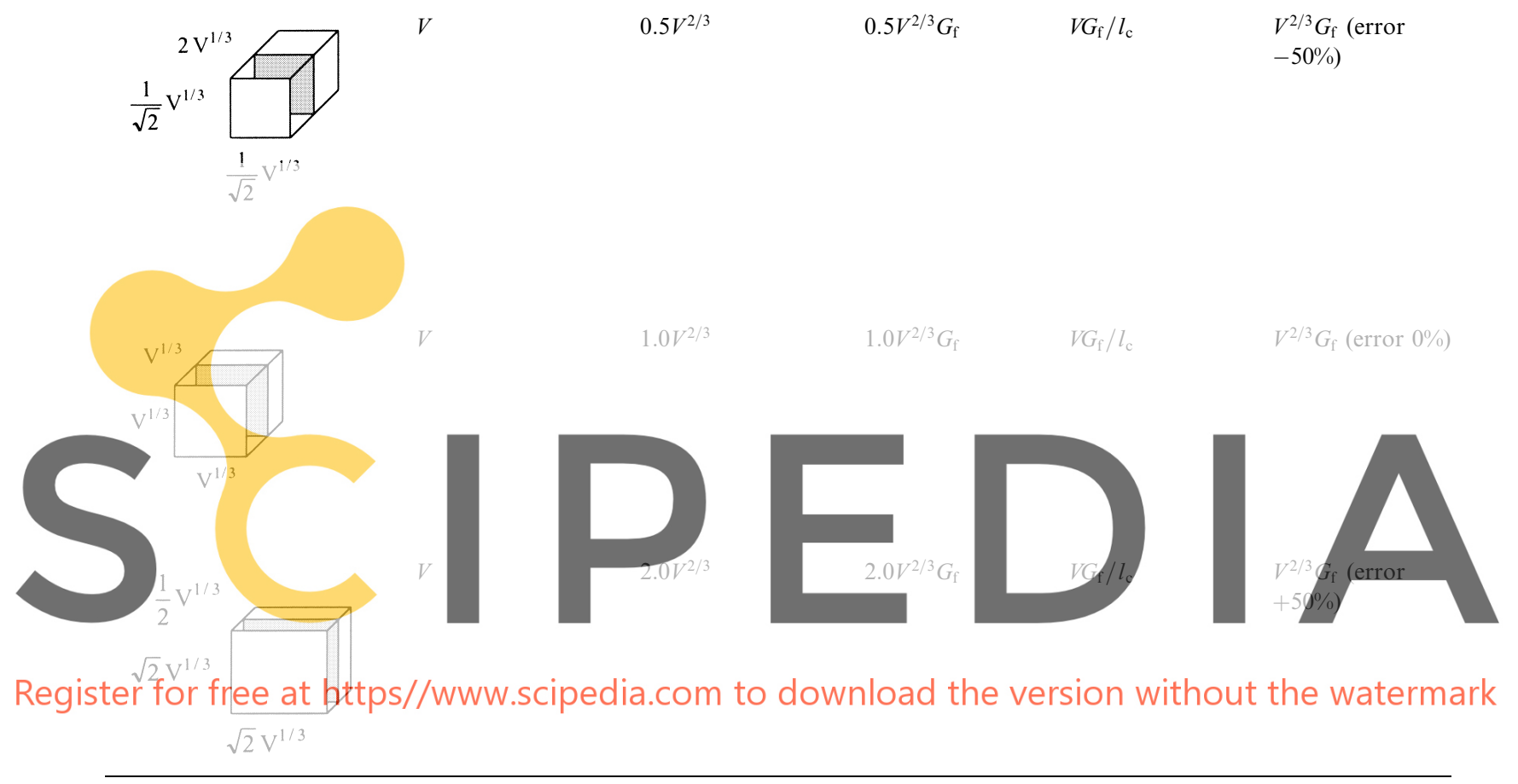

the characteristic length, even if theoretically defined, is of difficult practical evaluation and it strongly affects the results obtained both with non-local models and also the parameter $A$ (Eqs. (16) and (25)) of the previously described local model.

Another crucial point that supports the use of the proposed enhanced local method is that it does not need any increase of CPU time to be implemented with respect to the classical local approach, and needs much less CPU time than the non-local methods.

However, it is worth noting that the proposed approximate approach e.l.m. cannot completely eliminate the aspect of mesh dependency which manifests in terms of shape and dimension of the damaged zone.

\subsection{Limits of the single parameter scalar damage model}

The damage model and its evolution law used in the present work are of particular convenience because their easy implementation in existing finite element codes and because the small computational effort that is required in addition to the usual elastic analysis, if a suitable solution scheme is adopted. The form given to Eq. (14) allows to determine the local damage in a direct way, once the elastic stress (or strain) of the undamaged material is known and avoids the step-by-step integration of the damage evolution. These advantages are of capital importance if large scale problems are to be faced.

The presented single parameter damage model is incapable of taking into account the crack closure effect and the increase of the material strength with the rate of deformation. The presence of a single damage parameter to account for damaging caused by both tensile and compressive stress states produces the effect that, in contrast with the experimental evidences, the damage due to initially applied tensile strains causes an unrealistic loss of stiffness if subsequently compression strains 
are applied. Therefore, the damage surface changes homotetically as damage increases.

As a consequence, the proposed damage model can be conveniently used, as in this work, only for the analysis of problems with quasi-static monotonic increasing loads, but not to simulate problems with cyclic or dynamic actions. To face such a type of problems different damage models able to comply with the stiffness recovering and rate dependent effects, must be used (see e.g. the work by Dubè et al. [27], Faria and Oliver [28] and Saetta et al. [29]).

\section{Finite element formulation}

The local equilibrium condition of the continuum can be written as

$\sigma_{i j, j}+b_{i}=0 \quad$ on $\Omega, \quad \sigma_{i j} n_{j}=t_{i} \quad$ on $\Gamma$

where $\Omega$ and $\Gamma$ are the body volume and surface, $b_{j}$ is the vector of the mass loads, $n_{j}$ is the unit vector normal to the surface and $t_{i}$ is the vector of surface loads. Eq. (29)

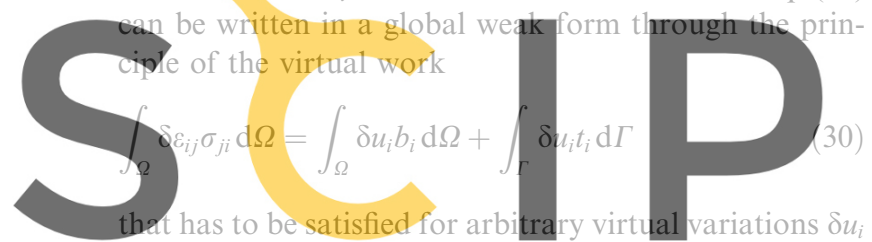
and $\delta \varepsilon_{i j}$ from the equilibrium position.

Register for quantitative solutions, the equilibrium Eq. (30)

The displacements $\mathbf{u}=u_{i}$, assumed as basic variables of the problem, are expressed in the whole domain by the global shape function matrix $\mathbf{N}$ and nodal value vectors a:

$\mathbf{u}=\mathbf{N a}$.

The strain tensor is written as

$\boldsymbol{\varepsilon}=\mathbf{L} \mathbf{u}=\mathbf{L N a}=\mathbf{B a}$,

where $\mathbf{L}$ is the strain operator and $\mathbf{B}$ is the strain matrix. After substitution of Eqs. (31) and (32) into Eq. (30), the following system results:

$\mathbf{K a}=\int_{\Omega} \mathbf{N}^{\mathrm{T}} \mathbf{b} \mathrm{d} \Omega+\int_{\Gamma} \mathbf{N}^{\mathrm{T}} \mathbf{t} \mathrm{d} \Gamma$

where $\mathbf{K}$ is the global stiffness matrix

$\mathbf{K}=\int_{\Omega} \mathbf{B}^{\mathrm{T}}(1-d) \mathbf{D B} \mathrm{d} \Omega$,

and $\mathbf{D}$ is the elasticity tensor of Eq. (1).

The system of Eq. (33) is non-linear due to the dependence of the damage parameter $d$ (that is of the stiffness matrix $\mathbf{K}$ ) on the strain tensor $\varepsilon$ (that is on the displacement vector a). Therefore, a step-by-step solution must be adopted, where the external loads on the right-hand side of Eq. (33) are applied incrementally.

Within each step the adoption of a regular NewtonRaphson algorithm for the solution of the non-linear system, with the proper tangent stiffness given by Eq. (22), would provide quadratic convergence to the solution. However, with a full Newton-Raphson scheme the tangent stiffness matrix has to be formed and refactorized (solved) for each iteration. Moreover, the tangent stiffness matrix becomes non-symmetric and the computational time drastically increases, so the advantages of using the e.1.m. instead of a non local model vanishes.

In our numerical tests, we have found that the adoption of a modified Newton-Raphson scheme (where the initial elastic or the secant stiffness matrix $\mathbb{D}^{\mathrm{S}}$ is used in substitution of the tangent stiffness) requires a computational time, to reach the same tolerance, which is smaller than that needed with the full Newton-Raphson scheme. In fact, the greater number of iterations necessary at each time step due to the crudeness of the predictor, is more than counterbalanced by the time-saving obtained avoiding the evaluation and the inversion of

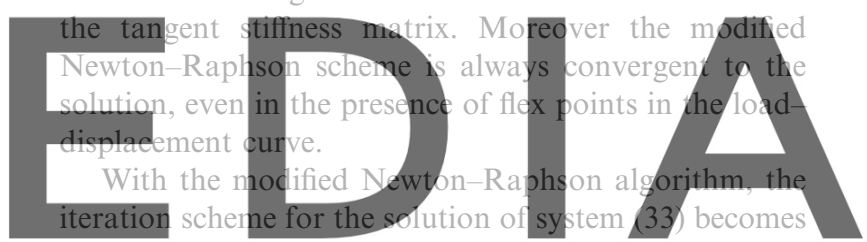

$\mathbb{K}_{s} \delta \mathbf{a}_{n}^{i}=\mathbb{F}_{n+1}-\mathbb{P}_{n+1}^{i}, \quad \mathbf{a}_{n+1}^{i+1}=\mathbf{a}_{n+1}^{i}+\delta \mathbf{a}_{n}^{i}$

download the version without the watermark where $n$ means the time step and $i$ is the iteration counter, and

$$
\begin{aligned}
& \mathbf{F}_{n+1}=\int_{\Omega} \mathbf{N}^{\mathrm{T}} \mathbf{b}_{n+1} \mathrm{~d} \Omega+\int_{\Gamma} \mathbf{N}^{\mathrm{T}} \mathbf{t}_{n+1} \mathrm{~d} \Gamma, \\
& \mathbf{P}_{n+1}^{i}=\int_{\Omega} \mathbf{B}^{\mathrm{T}} \boldsymbol{\sigma}_{n+1}^{i} \mathrm{~d} \Omega .
\end{aligned}
$$

The convergence norm used in the numerical tests is

$h_{n+1}^{i}=\frac{\left|\mathbf{F}_{n+1}\right|-\left|\mathbf{P}_{n+1}^{i}\right|}{\left|\mathbf{F}_{n+1}\right|-\left|\mathbf{F}_{n}\right|}<t$,

where $|\cdot|$ indicates the Euclidean norm. The solution is iterated until the tolerance $t$ is fulfilled.

\section{Numerical applications developing of the shear reten- tion factor}

\subsection{The numerical finite element codes}

Two different numerical codes based on the scalar damage model described before have been developed and tested: a local three-dimensional finite element code 


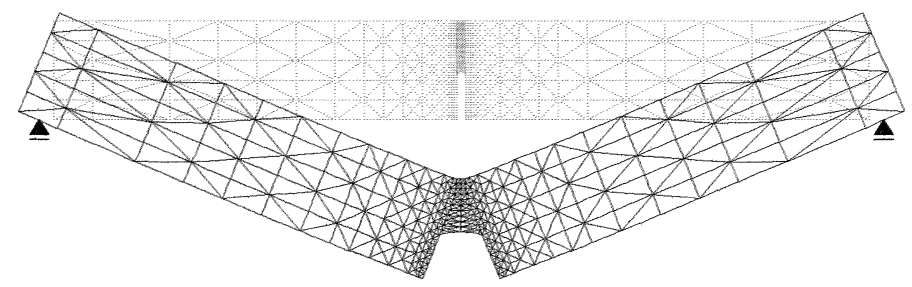

Fig. 3. Discretisation used in the FE simulation of fracture energy measurement test of concrete: deformed mesh at failure.

developed at the UPC and a local/non-local twodimensional finite element code developed at the University of Padova. Both numerical codes are able to consider steel reinforcement having uniaxial elastoplastic isotropic constitutive behaviour, allowing for the analysis of reinforced as well as plain concrete structures. The mathematical model considers perfect adhesion between the concrete and the steel. The presence of uni-dimensional elements representing the reinforcement steel contributes to the spreading of the damage. A modified Newton-Raphson algorithm, that uses the initial elastic stiffness matrix as iteration matrix, has been adopted for the solution of the non-linear system.

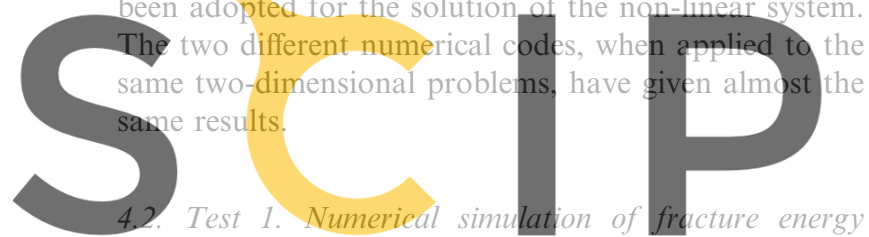

measurement test

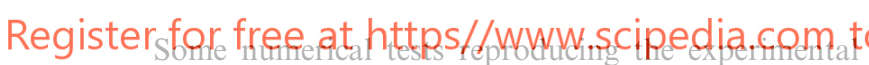
procedures for fracture energy measures of cement paste on parallelepiped notched specimens have been performed. The tests simulate the numerical experiments done by Horvat and Persson [30] and allows to validate the e.l.m. previously described.

In all the numerical examples the same mesh topology, made of six-node isoparametric triangular elements, has been used. Different scaling factors of the nodal coordinates have been used along $X$ and $Y$ directions to match the real dimension of the specimens. The concrete characteristics are summarised in Table 2, the discretisation and the main results obtained from the analyses are drafted in Figs. 3 and 4. The tolerance limit $t$ controlling the iteration scheme has been set in $0.5 \%$. With the modified Newton-Raphson algorithms using

Table 2

Mechanical properties of concrete for fracture energy test 1

\begin{tabular}{ll}
\hline Elastic modulus & $E_{\mathrm{c}}=31 \mathrm{GPa}$ \\
Poisson's ratio & $v=0.20$ \\
Uniaxial compressive strength & $f_{\mathrm{c}}=35 \mathrm{MPa}$ \\
Uniaxial tensile strength & $f_{\mathrm{t}}=6.0 \mathrm{MPa}$ \\
Fracture energy & $G_{\mathrm{f}}=60 \mathrm{~N} / \mathrm{m}$ \\
\hline
\end{tabular}

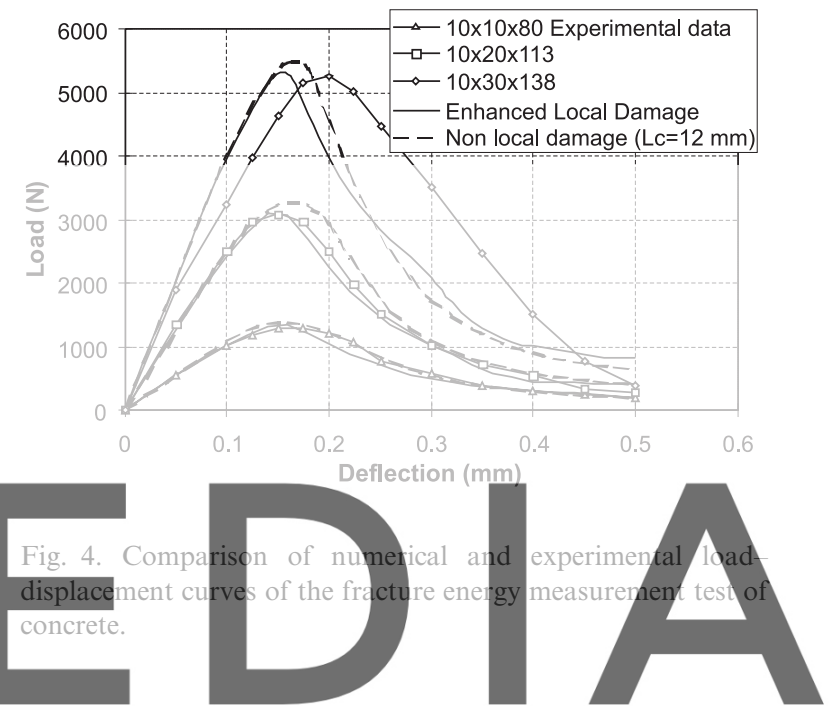

the initial stiffness matrix, the number of iteration necessary to reach convergence is resulted to be about 50-70 download the versinn without the watermark

tensively damaged. Similar conditions have been also obtained in all the following examples.

Comparison between the solutions obtained with the non-local approach and the enhanced local approach has been made to assess the effectiveness and practical relevance of the adopted approximate procedure. It has been observed that the results obtained with the local solution with constant $l_{\mathrm{c}}$ are strongly dependent on the mesh refinement and the softening branches of the curves become shorter as the mesh size decreases. Moreover, the non-local approach is strongly dependent on the assumed value of the characteristic length $l_{\mathrm{c}}$. Here, the best fit over all the three specimen sizes has been derived using $l_{\mathrm{c}}=12 \mathrm{~mm}$. In general good solutions have been obtained with the e.l.m. which has the advantage of not requiring the $l_{\mathrm{c}}$ value as an input datum.

\subsection{Test 2. Four point bending test of beam failing in shear}

The test considers the reinforced concrete beam of Fig. 5, which was experimentally loaded up to failure by 
Walraven [7]. The beam has no shear reinforcement. The experimental observation showed that failure was imputable to the shear force, after the developing of diagonal cracks which reduces the available area of concrete in the vicinity of the load points. The failure load was of about $70 \mathrm{kN}$; the theoretical ultimate flexure limit strength of the beam would correspond to a load of about $120 \mathrm{kN}$.

The problem was numerically simulated with (a) the three-dimensional numerical codes using a $4 \times 16 \times 1$ mesh (representing only half of the symmetric beam) made of three-dimensional 20 node isoparametric elements (Fig. 5); and (b) with the two-dimensional computer code using a 5-rows for 34-columns mesh made of

Table 3

Mechanical properties of concrete and reinforcing steel for the four point bending test 2

\begin{tabular}{ll} 
Concrete & \\
Elastic modulus & $E_{\mathrm{c}}=28 \mathrm{GPa}$ \\
Poisson's ratio & $v=0.20$ \\
Uniaxial compressive strength & $f_{\mathrm{c}}=30 \mathrm{MPa}$ \\
Uniaxial tensile strength & $f_{\mathrm{t}}=2.5 \mathrm{MPa}$ \\
Fracture energy & $G_{\mathrm{f}}=10 \mathrm{~N} / \mathrm{m}$ \\
Reinforcing steel & \\
Elastic modulus & $E_{\mathrm{s}}=206 \mathrm{GPa}$ \\
Yielding stress & $f_{\mathrm{y}}=440 \mathrm{MPa}$ \\
Ultimate strength & $f_{\mathrm{s}}=550 \mathrm{MPa}$ \\
Hardening parameter & $H=20 \mathrm{GPa}$ \\
Deformation at failure & $e_{\mathrm{su}}=8 \%$ \\
\hline
\end{tabular}

eight-noded isoparametric elements, with the plane stress assumption.

The properties of the concrete and of the reinforcing steel used in the test are summarised in Table 3.

The resulting numerical load-displacement curve is plotted in Fig. 6 (continuous line labelled $\left.\beta_{\mathrm{S}}=0.00\right)$ and
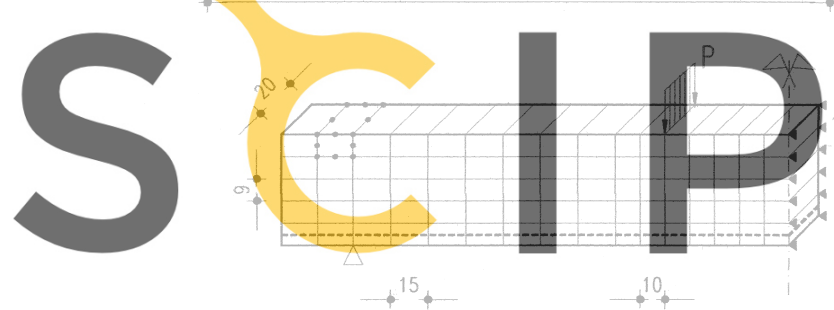

10

Register for free at https / www scipedia,com to three-dimensional FE mesh.

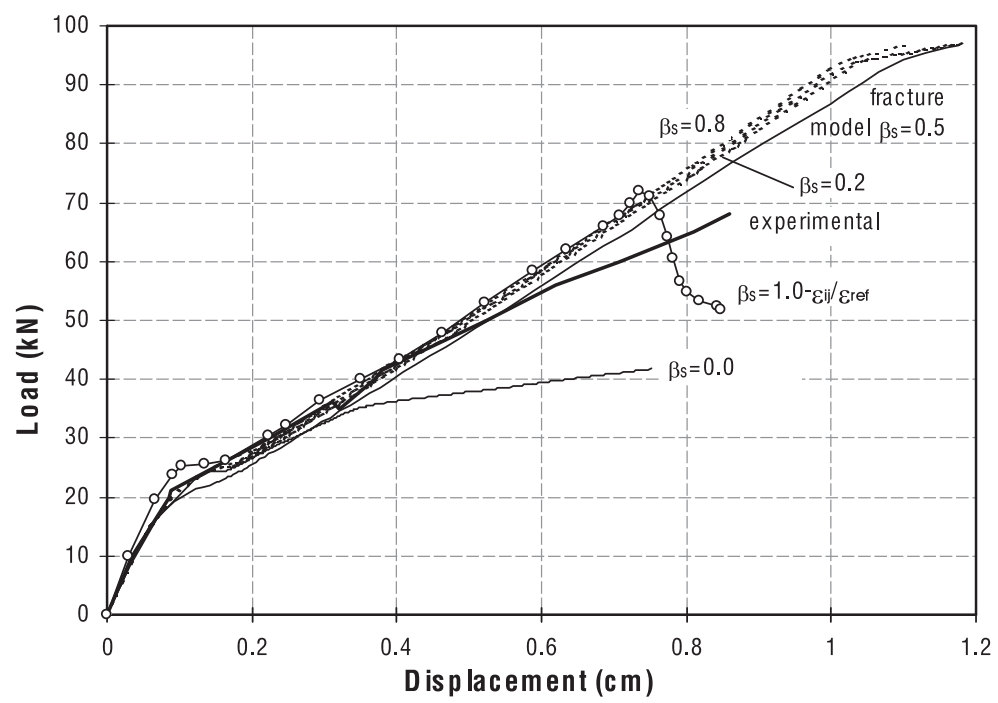

Fig. 6. Four point bending test: comparison between the numerical and experimental load-deflection curves (the deflection of the points of load application is represented). 
points, strongly reduces the shear strength of the beam and leads to a sharp reduction of the corresponding stiffness. The experimental observation was that vertical cracks formed first in the central zone, where the bending moment is maximum and constant. On subsequent loading the stresses rotated and new inclined cracks formed in the region between the point load and the supports. Despite the coarseness of the mesh, the damage distributions at different load levels plotted in Fig. 7 confirm the experimental observation and testifies the presence at incipient failure of a diagonal band at about $45^{\circ}$, in the same position as the experimental shear cracks. It penetrates under the compression zone, reducing the resistant area, finally leading to the failure. In Fig. 8 the progressive passage from a De Saint Venant compressive stress distribution, for low load level, to a Mörsch type resistant mechanism for the ultimate load, is recognisable.

In the construction practice it is well known that structural elements without shear reinforcement exhibit appreciable shear bearing capacity. Such an evidence is taken into account in all the building codes that, below an allowable shear stress level, admit the design of structural members without transversal shear reinforcement.

The inability of the numerical model to predict correctly the experimental behaviour is due to the fact that it does not consider the various mechanisms of shear transfer that have been evidenced and reviewed in Ref. [31]. Among these mechanisms, which do not require web reinforcement to be activated, some are implicitly accounted for by the damage model (arch mechanism and concrete cantilevers), others are not considered. The most relevant is the "interface shear transfer" or "friction" that is the bearing capacity due to aggregate interlocking developing between two slipping surfaces of an open crack. This residual capacity is a function of geometry, of surface conditions and of material characteristics. It is of fundamental importance to explain the greater shear capacity that concrete structures show

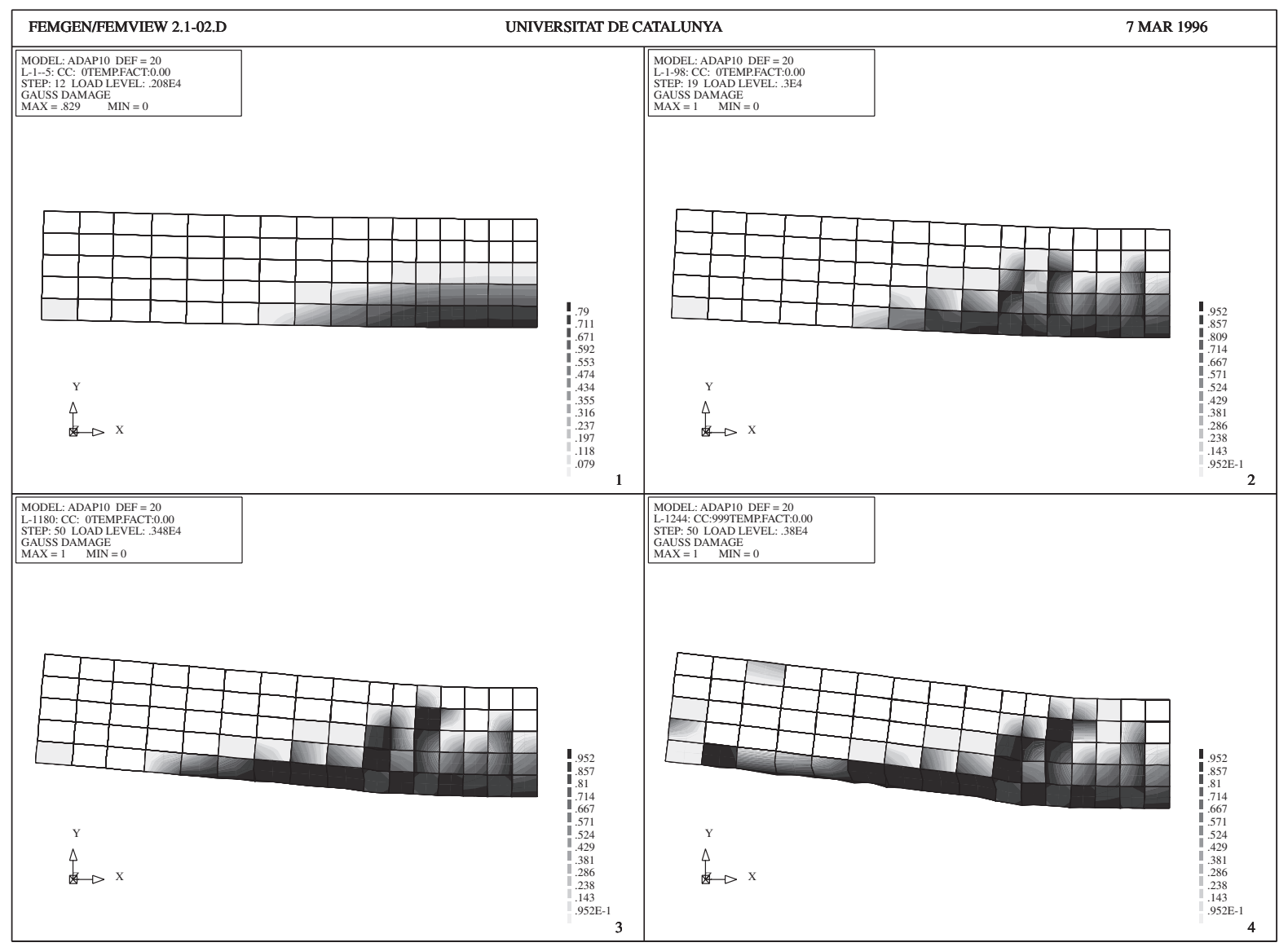

damage pattern at various load levels - shear retenction factor 0.0

Fig. 7. Four point bending test: damage distribution at load levels $21,30,34$ and $38 \mathrm{kN}$ (analysis without shear retention factor). 


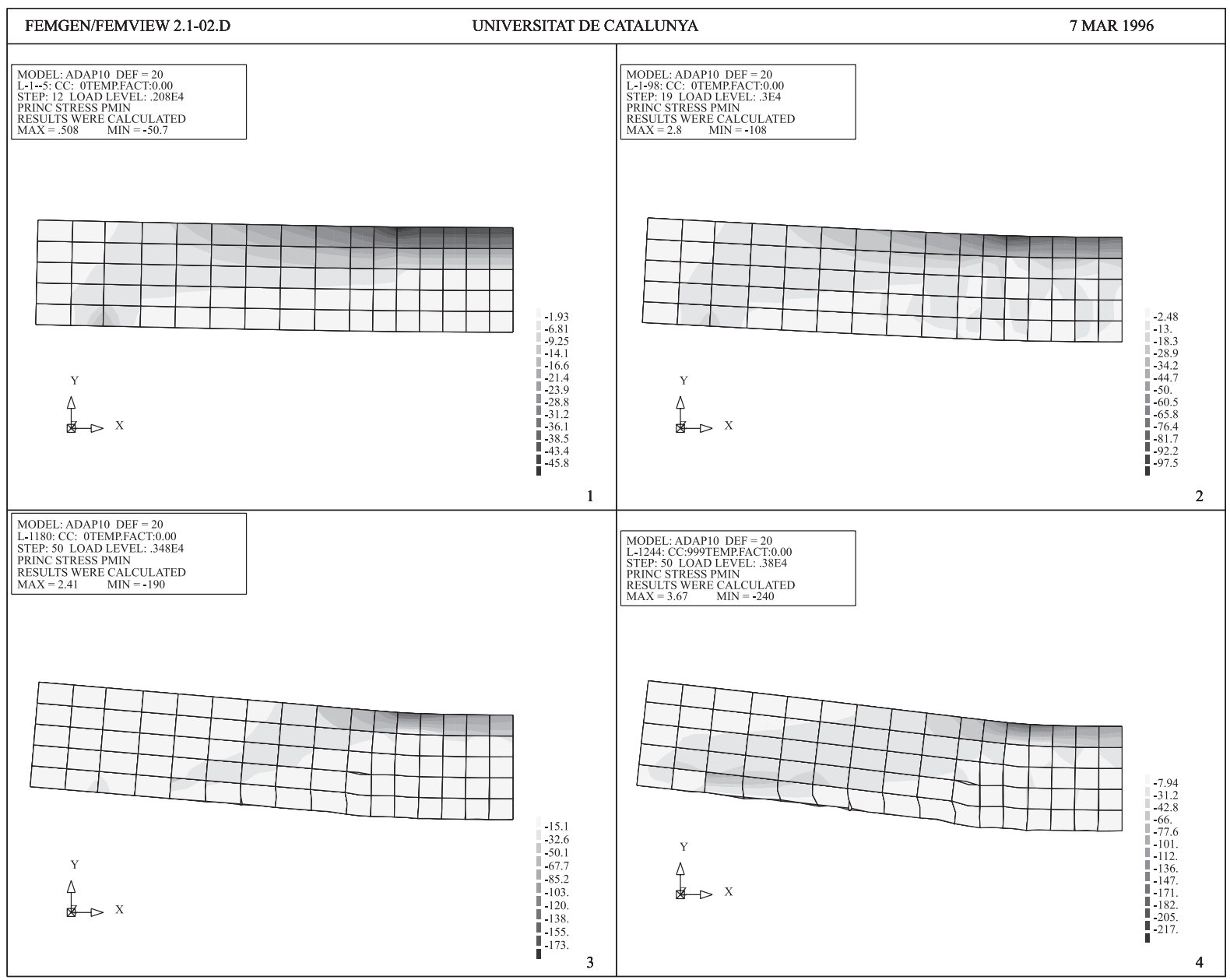

min principal stress at various load levels - shear retenction factor 0.0

Fig. 8. Four point bending test: minimum principal stress at load levels 21, 30, 34 and $38 \mathrm{kN}$ (analysis without shear retention factor).

with respect to that calculated if only shear transfer through the compressed zone is considered.

In the form presented so far, the damage model is incapable of preserving a shear transfer caused by the aggregate interlocking. In fact, because of the isotropy of the mechanical behaviour, the damage induced by the tension affects in the same amount both the compressive and the shear stiffness. Eqs. (5) and (22) clearly show that when damage approaches 1 , both the secant and tangential stiffness matrices tend to be identically null, in regard to the axial and the shear stresses. Such a drawback can be bypassed with the introduction of a shear retention factor as explained hereafter.

\subsection{Developing of a shear retention factor}

The incapability of the numerical models to describe the aggregate interlocking shear resistance mechanism has been already encountered in the so-called crack models and it has been often solved with the introduction of a "shear retention factor" able to assure a residual friction along the crack directions. Of this type is the model proposed by Cervera et al. [32-34], which assigns a reduced value for the shear stiffness in the direction parallel to the crack:

$G=\left(1-\beta_{\mathrm{S}}\right) G_{0}$

with $\beta_{\mathrm{S}}$ equal 0.00 for the undamaged material or for instance 0.5 through an open crack so avoiding the complete loss of shear transfer.

In a similar way a "shear retention factor" for the damage model is proposed in this work. It modifies the secant stiffness matrix of the material in the following form:

$\sigma_{i j}=\left[1-d+\left(1-\delta_{i j} \delta_{k l}\right) \beta_{\mathrm{S}} d\right] D_{i j k l}^{0} \varepsilon_{k l}=D_{i j k l}^{s *} \varepsilon_{k l}$ 
which for the normal stresses $(i=j$ and $k=l)$ gives the normal secant stiffness matrix $\sigma_{i j}=(1-d) D_{i j k l}^{0} \varepsilon_{k l}$ while for the shear stresses introduces a reduction of the damage action in order to assure a minimum shear strength even for the completely damaged material

for $d=1, i \neq j, k \neq 1 \rightarrow \sigma_{i j}=\beta_{\mathrm{S}} D_{i j k l}^{0} \varepsilon_{k l}$.

From Eq. (1), by analogy, the new expression of the Gibbs' elastic free energy becomes

$\Psi^{*}=\frac{1}{2}\left[1-d+\left(1-\delta_{i j} \delta_{k l}\right) \beta_{\mathrm{S}} d\right] \varepsilon_{i j} D_{i j k l}^{0} \varepsilon_{k l}$

that differs only for the part associated with the shear deformation:

$\Psi^{*}-\Psi=\frac{1}{2}\left[\left(1-\delta_{i j} \delta_{k l}\right) \beta_{\mathrm{S}} d\right] \varepsilon_{i j} D_{i j k l}^{0} \varepsilon_{k l}$.

Such an expression, due to the properties of the elastic stiffness matrix and the Kronecker delta, can be rewritten as

$\Psi^{*}-\Psi=\frac{1}{2} \beta_{\mathrm{S}} d G \varepsilon_{i j} \varepsilon_{i j}, \quad i \neq j$

that is surely positive assuring the positiveness of $\Psi^{*}$. From an energetic point of view, the introduction of the shear retention factor implies a greater storage of free energy. At least, for beams, where the shear deformation is negligible respect to the flexural one, the magnitude of the energetic difference is small if compared to that of the original damage model and therefore the global structure deformation is not appreciably influenced.

Eq. (39) has been implemented in the numerical model assuming, as first attempt, $\beta_{\mathrm{S}}$ as a constant. Various numerical test with $\beta_{\mathrm{S}}$ varying from 0.0 (without shear retention factor) to 1.0 (damage ineffective for shear stress) have been performed. The sensitivity of deformability and damage evolution to the changes of $\beta_{\mathrm{S}}$ has been explored finding out that the results are almost identical for each value of $\beta_{\mathrm{S}}$ greater than 0.2 while lower values are ineffective (e.g. the continuous thin lines labelled " $\beta_{\mathrm{S}}=0$ " in Fig. 6). The introduction of a high value of the shear retention factor introduces a new trouble: the failure mechanism changes from a shear type to a flexural type and the strength capacity of the structure is overestimated (see the dotted lines in Fig. 6).

From these observations it results that the assumption of a constant shear retention factor is not realistic and a more complex formulation needs to be explored. The new formulation for $\beta_{\mathrm{S}}$ ought to take into account that the friction due to the roughness of the crack surface must decrease as the opening of crack increases, being the friction coefficient strictly linked to the value of shear deformation. On this basis, the following evolution law for the shear retention factor has been proposed:

$\beta_{\mathrm{S}, i j}=1-\left|\frac{\varepsilon_{i j}}{\varepsilon_{\mathrm{ref}}}\right| \geqslant 0, \quad i \neq j$, where $\varepsilon_{i j}$ denotes the shear deformation and $\varepsilon_{\mathrm{ref}}$ is a reference value of the deformation which has to be determined through numerical fitting of the experimental results. The expression (44) of the s.r.f. obviously is only one of all those that could be used, but as will be shown hereafter, such a choice has given appreciable results.

In the four point bending tests, using a value for $\varepsilon_{\text {ref }}=0.8 \%$, the curve with circle symbols in Fig. 6 has been obtained. It shows a good agreement with the experimental one in terms of the value of the collapse load, even if the correspondent displacement is slightly different. However the magnitude of such a difference is comparable with the scattering usually recorded during experimental tests.

A numerical analysis employing the crack model proposed by Cervera et al. [32-34] was also done for comparison. The same material parameters were adopted together with the constant $\beta_{\mathrm{S}}=0.5$. The loaddisplacements curve from this analysis is plotted in Fig. 6 (continuous line labelled with "fracture model $\beta_{\mathrm{S}}=0.5$ ") together with those obtained with the damage model. Even for the crack model the introduction of a constant s.r.f. transforms the shear failure in a flexural one, while the shear failure disappears. Such a consideration allows us to suppose that expression (44) could be conveniently used even in a crack-based constitutive model.

Theoretically the value of $\varepsilon_{\text {ref }}$ should depend on the components of concrete and in particular on the dimension of the aggregate. Actually, in all the proposed numerical tests, which consider various concrete classes and also high strength concrete (whose results will be illustrated in the following section), the value of $\varepsilon_{\text {ref }}=0.8 \%$ has always been used. This demonstrated that for the proposed damage model this represents a mean value that reproduces well the behaviour of all the analysed concrete structures. Necessarily $\varepsilon_{\text {ref }}$ must change if another different damage model, having a different shape of the damage surface, is adopted.

\subsection{Test 3. Fitting of experimental results from normal and high strength concrete beam}

A series of simply supported beams, made of normal and high strength concrete, reinforced with only flexural bars, have been cast and loaded up to failure at the Department of Construction and Transportation of the University of Padova [8]. All the beams have the same section $b=14 \times h=25 \mathrm{~cm}$, the load was applied in the centre of the beam, or in two points at the third of the length, in order to have three different values of the moment over shear ratio $a / d$. The complete description of the material characteristics and the specimen details are given in Tables 4 and 5, respectively. Some of the tested beams have failed in shear, others under bending. The numerical simulation of this collection of tests 
represents a true benchmark for the validation of the damage model with different failure mechanisms.

For these analyses a mesh composed of 38 columns and four rows of eight-noded isoparametric elements was employed. The finite element discretisation, the typical deformation, the damage distribution and the pattern of the minimum principal stress for the displacement level of $1.4 \mathrm{~cm}$ (just after the point of peak load) of the beam C60_A12_a/d4 are in Fig. 9. It demonstrates the developing of a damaged zone up to the point of load application and in correspondence the decrease of stress (that is of the bearing capacity) in the

Table 4

Mechanical properties of concrete and reinforcing steel used in test 3

\begin{tabular}{llll}
\hline & Class & & \\
\cline { 2 - 4 } & $30 \mathrm{MPa}$ & $60 \mathrm{MPa}$ & $100 \mathrm{MPa}$ \\
\hline Concrete & & & \\
Elastic modulus, $E_{\mathrm{c}}$ & $34.3 \mathrm{GPa}$ & $37.4 \mathrm{GPa}$ & $46.9 \mathrm{GPa}$ \\
Poisson's ratio, $v$ & 0.20 & 0.20 & 0.20 \\
Uniaxial compressive & $22 \mathrm{MPa}$ & $43 \mathrm{MPa}$ & $98 \mathrm{MPa}$ \\
strength, $f_{\mathrm{c}}$ & & & \\
Uniaxial tensile & $2.7 \mathrm{MPa}$ & $3.9 \mathrm{MPa}$ & $5.6 \mathrm{MPa}$ \\
strength, $f_{\mathrm{t}}$ & & & \\
Fracture energy, $G_{\mathrm{f}}$ & $60 \mathrm{~N} / \mathrm{m}$ & $80 \mathrm{~N} / \mathrm{m}$ & $80 \mathrm{~N} / \mathrm{m}$ \\
Reinforcing steel & & & \\
Elastic modulus, $E_{\mathrm{s}}$ & & $206 \mathrm{GPa}$ & \\
Yielding stress, $f_{\mathrm{y}}$ & & $540 \mathrm{MPa}$ & \\
Ultimate strength, $f_{\mathrm{s}}$ & & $640 \mathrm{MPa}$ & \\
Hardening parameter, $H$ & & $0.5 \mathrm{GPa}$ & \\
Deformation at failure, $\varepsilon_{\mathrm{su}}$ & & $20 \%$ & \\
\hline
\end{tabular}

compression zone. The numerical results are compared with the experimental curves in Fig. 10. The displacements are normalised with respect to the beam's length in order to be joined into a unique graph. The model is able to reproduce all the principal experimental evidences, in particular it discerns between shear and flexural failure. Also, the magnitudes of the numerical failure load and beam stiffness are fitted within a scattering that is comparable with the uncertainties of the experiments.

In the laboratory procedures the beams with the lower value of moment over shear ratio $a / d$ were in reality pieces cut from the $300 \mathrm{~cm}$ length beams after experimenting on them, therefore they were already cracked and damaged before the starting of the load process. The images of concrete damage and steel plastic deformation have been taken from the numerical analyses with $a / d=4.34$ and used as initial conditions in the following calculations of the beams with $a / d=3$. However, for these beams the differences in deformation between numerical and experimental results are generally more evident than in the other tests while the model still correctly predicts the ultimate load. The loadingunloading cycles that have been sometimes applied to beams in the laboratory were not considered in the numerical analyses.

It has to be pointed out again that in all the tests the value $\varepsilon_{\text {ref }}=0.8 \%$ has been assumed.

\subsection{Test 4. The construction of the "shear valley"}

As a last validation test of the numerical model, the construction of the "shear valley" for a beam without web reinforcement has been developed.

Table 5

Experimental details of the beams of test 3

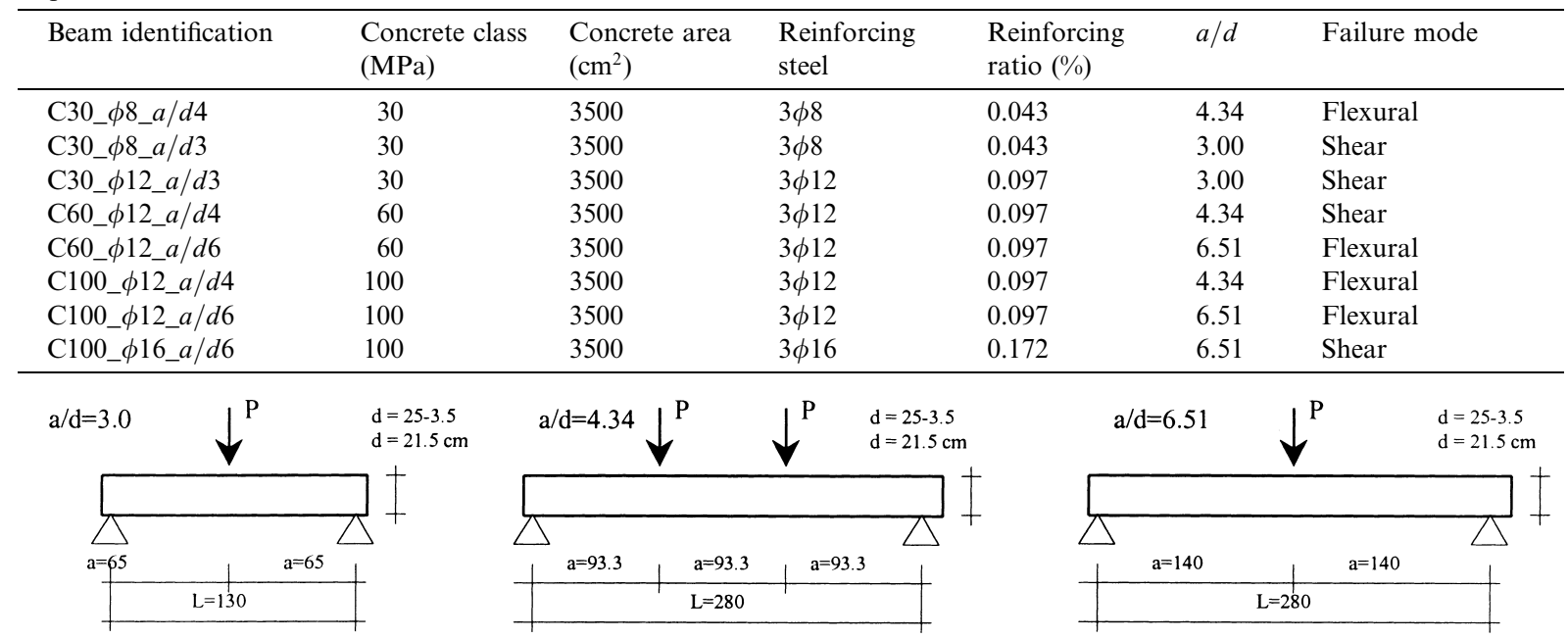



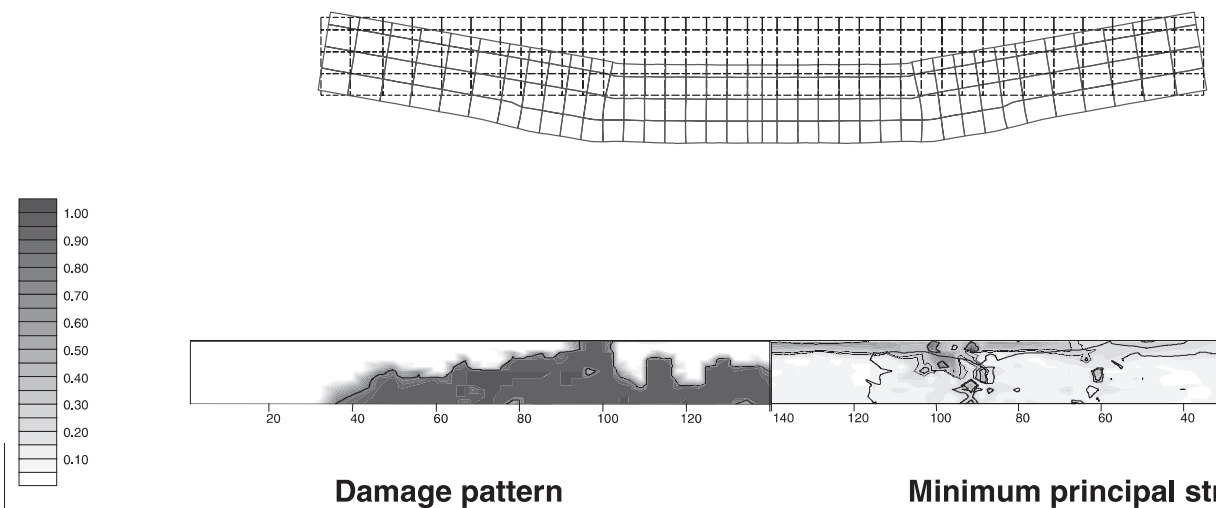

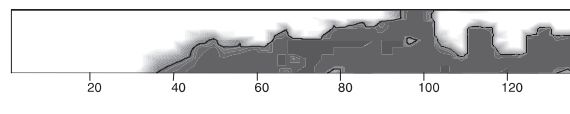

Damage pattern

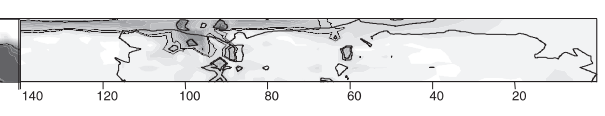

Minimum principal stress

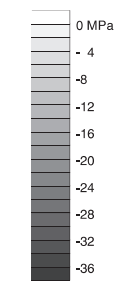

Fig. 9. Test 3. FE mesh used in the analysis of the beam C60_A12_a/d4. Beam deformation, damage pattern and minimum principal stress distribution at incipient failure.

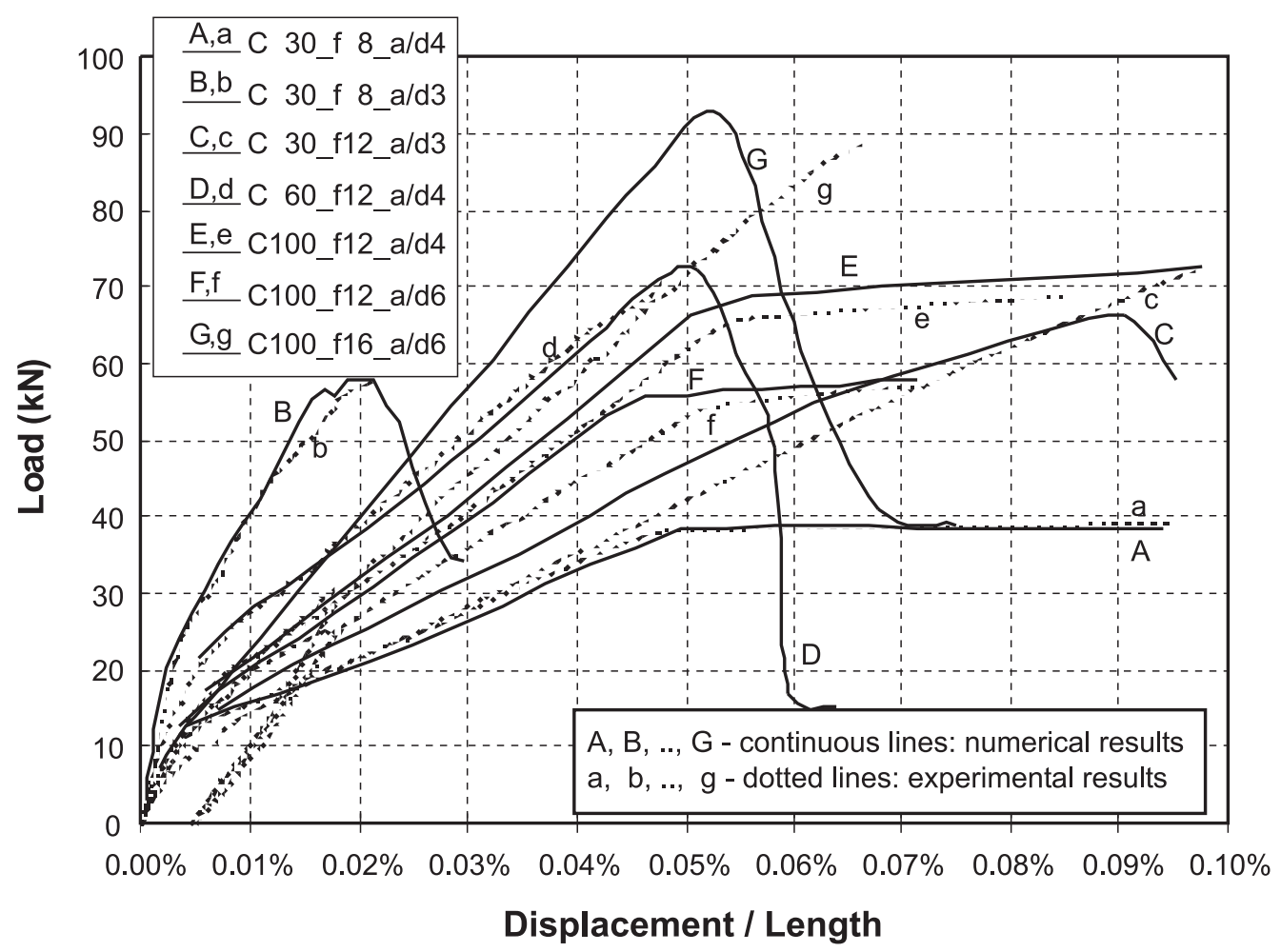

Fig. 10. Test 3. Comparison between the numerical and experimental load-displacement curves.

The shear valley, discussed and experimentally obtained by Kani [9], individuates for a beam the range of $a / d$ (the shear span to depth ratio, which can also be expressed in terms of the moment and the shear as $a / d=(V \times a) /(V \times d)=M /(V \times d)$ [35] $)$, for which failure is caused by shear and not by bending, i.e. where the flexural capacity of the beam is not attained. For a rectangular beam, without shear reinforcement and longitudinal reinforcement equal to $2.8 \%$, subjected to a four point bending test, the shear valley (Fig. 11) is located between $a / d=1$ and $a / d=7$. For greater values of $a / d$, bending becomes more relevant than shear and the failure happens due to yielding of the reinforcement or crushing of the compressed concrete. For lower 


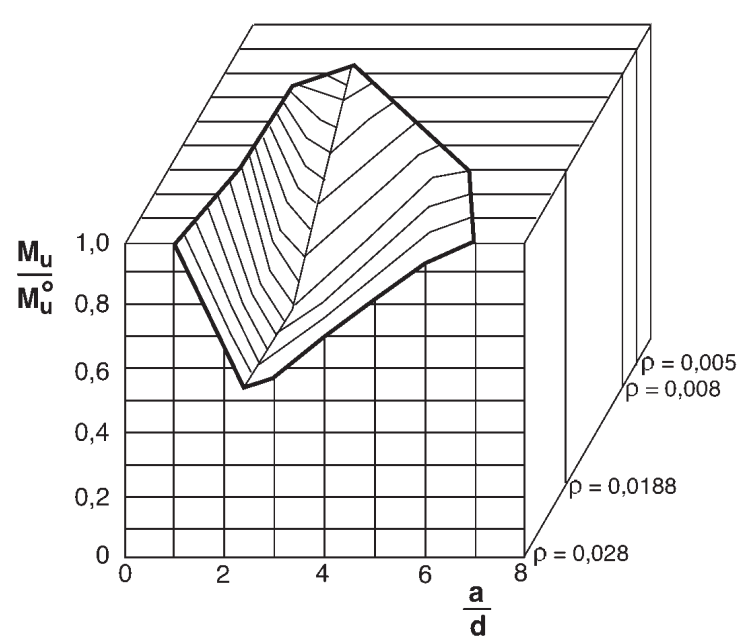

Fig. 11. Experimentally obtained shear valley for a rectangular beam without shear reinforcement [9].

values of $a / d$ the loads are directly transmitted to the support through a compressed strut, without appreciable forces on the beam. The depth of the valley increases with the amount of flexural reinforcement. To avoid brittle shear type failures, shear reinforcement must be designed to cover the shear valley.

On a beam with dimensions $14 \times 25 \times 300 \mathrm{~cm}^{3}$, made of concrete of class C100 (Table 4), several analyses were performed, varying both the position of the loads from the centre to the support (i.e. varying the value of $a / d$ ) and the amount of longitudinal reinforcement $\left(\mu_{\mathrm{S}}=\right.$ $A_{\mathrm{S}} /(b / d)=1.1,1.8,2.5$ and $\left.3.0 \%\right)$. The results of these studies are summarised in Fig. 12, where the load-displacement curves for the beam with $\mu_{\mathrm{S}}=1.8 \%$ are represented for different positions of the points of load application, and Fig. 13 which illustrates the obtained shear valley.

The closure of the shear valley for low values of $a / d$ was impossible to obtain since for the numerical loading and boundary conditions, where in reality displacements were imposed to the loaded point and the supports were nodal constraints, the splitting failure of concrete over the supports was always reached before the shear failure. Nevertheless, the numerical results for $a / d$ greater than 2 are in good agreement with those obtained by Kani [9].

\section{Conclusion}

A local isotropic scalar model able to simulate the mechanical behaviour of quasi-brittle materials, such as concrete, has been described. The damage is directly related to the effective stress of the material through a

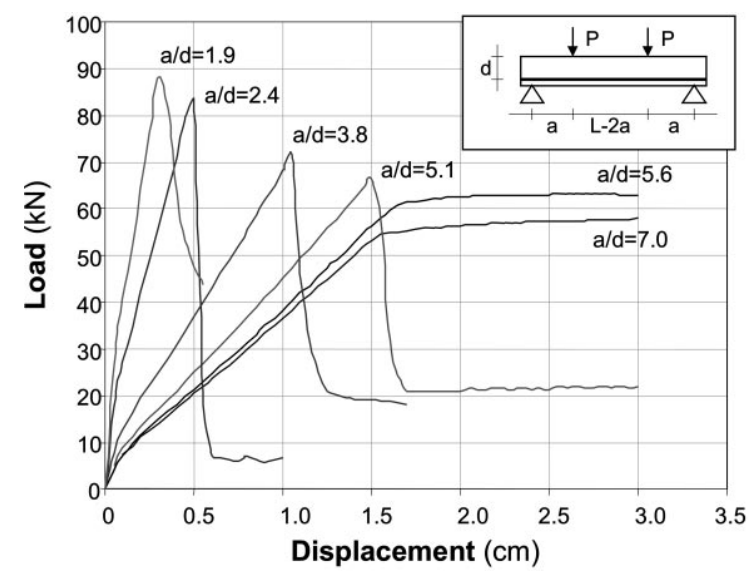

Fig. 12. Test 4. Load-displacement curves for the beam with $\mu_{\mathrm{S}}=2.8 \%$ for different values of $a / d$.

suitable exponential equation in which only one material parameter, that is the fracture energy, needs to be given together with the classical material mechanical characteristics. The evolution law of damage is described with an associated plasticity type law.

This model is suitable for the study of quasi-static problems where monotonically increasing loads are applied. Due to its simplicity, it is of clear and immediate applicability and can be easily implemented in existing finite element codes.

The problems of localisation and mesh dependency, as far as the energy aspect is concerned, typical for the analysis involving strain-softening materials, have been overcome with the use of the enhanced local method. In this method a characteristic internal length, linked to the mesh dimension, is employed instead of the characteristic fracture length. This assumption, whose effectiveness have been proved both analytically (Table 1) and numerically (test 1 ), joins the numerical advantages of the local model with the necessity of adopting suitable procedures to overcome the localisation problems.

In this work, the model was further enriched with the introduction of a shear retention factor that accounts for the well-known experimental observation that a not negligible quota of shear stress is transmitted through an open crack due to the effect of friction between the two surfaces of the crack. Several calculations were performed to find out a suitable expression for the s.r.f. variable with the deformation and to assess the influence of this factor on the global and local results obtained with the numerical model. Despite of the simplicity of this improvement, which does not require additional calculation, no negative effects have been found, while a good agreement with experimental data was obtained. The introduction of the shear retention factor has made it possible to reproduce numerically the experimental 

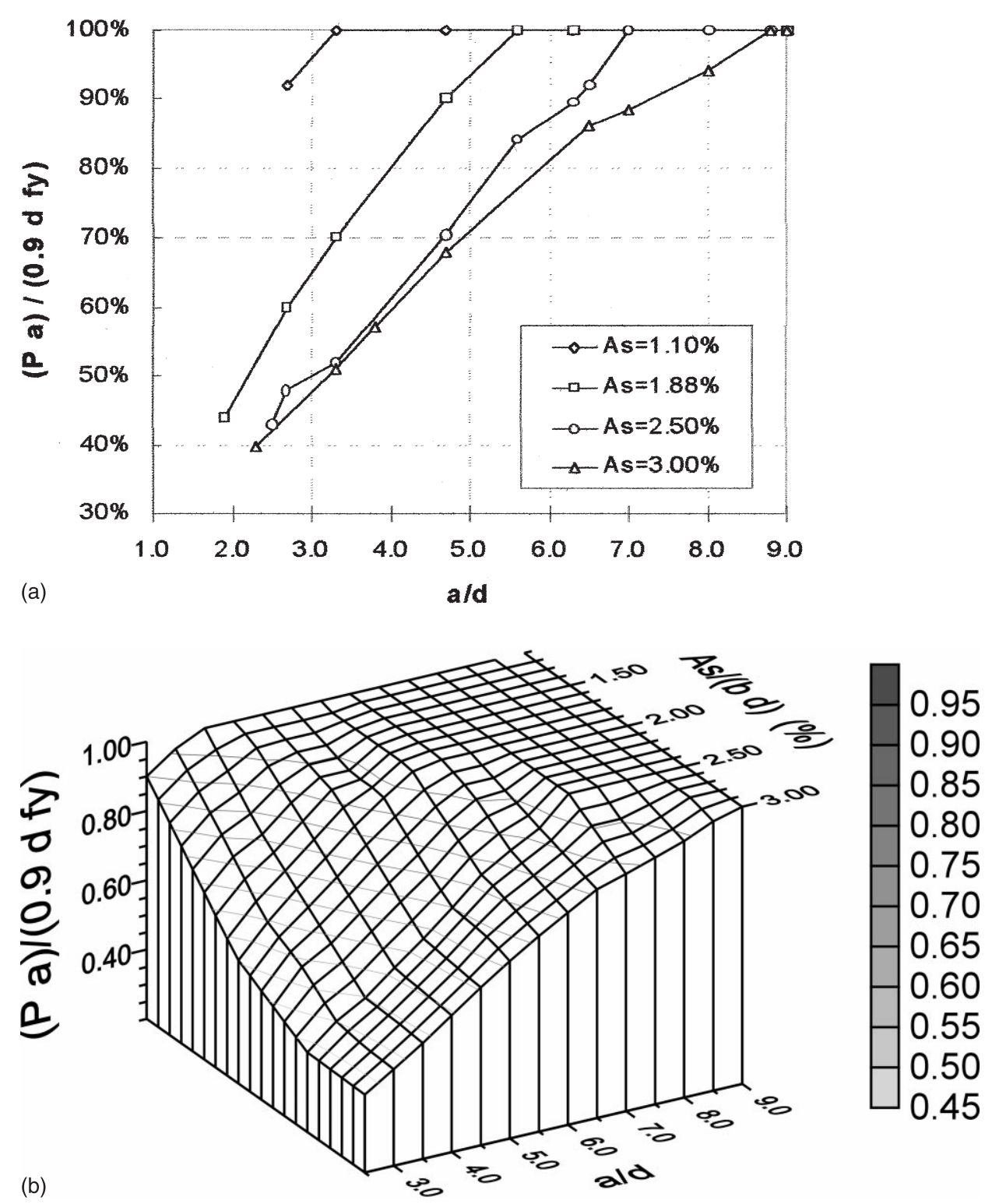

Fig. 13. Test 4. Numerically obtained shear valley for a rectangular beam without shear reinforcement.

evidences of beams failing in shear that have been the objective of the numerical tests $2-4$.

In conjunction with a modified Newton-Rapshon solution scheme, where the secant or the initial stiffness matrices have been used, the model demonstrated to be stable and accurate. The simplicity and the low requirement of computing time of the model make it suitable for the practical solution of large scale problem.

The new features described in this work, the shear retention factor and the enhanced local method, have in future to be extended to more sophisticated damage models for example able to comply with the rate de- pendent effects and the crack closure effect, which implies stiffness recovery under alternate loads.

The effect of the bond slip between concrete and reinforcement on the distribution and width of cracks have been recognized in Refs. [25,36], with reference to crack models. Further researches are needed to investigate such effect within the framework of a damage approach. In fact, the damage which grows in the vicinity of a crack naturally induces a weakness of the concrete intimately connected with the steel, and therefore the bond slip and the tension stiffening effect as well, are in some way implicitly accounted for with the damage model. 


\section{Acknowledgements}

Financial support of the International Center for Numerical Methods in Engineering of Barcelona, Spain, which made this research possible, is gratefully acknowledged. Many thanks also to Alberto Manganaro for his actual help in developing the numerical tests.

\section{References}

[1] Kachanov L. Time of rupture process under creep conditions. Izvestia Akademii Nauk 1958;8:26-31 [in Russian].

[2] Simo JC, Ju J. Strain and stress based continuum damage models - part I: formulation. Int J Solids Struct 1987; 23:281-301.

[3] Lubliner J, Oliver J, Oller S, Onate E. A plastic-damage model for concrete. Int J Solids Struct 1989;25:299-326.

[4] Oliver J, Cervera M, Oller S, Lubliner J. Isotropic damage models and smeared cracked analysis of concrete. Proc. 2nd ICCAADS, vol. 2. Zee Am See, Swansee: Pineridge Press; 1990. p. 945-58.

[5] Saetta A, Scotta R, Vitaliani R. Coupled environmentalmechanical damage model of RC structures. J Engng Mech ASCE 1999;125(8):930-40.

[6] Scotta R. Analisi numerica di strutture in calcestruzzo mediante modelli di danno. PhD Thesis, Department of Construction and Transportation, University of Padova, Italy, 1997 [in Italian].

[7] Walraven JC. The influence of depth on the shear strength of light-weight concrete beams without shear reinforcement. Report 5-78-4, Stevin Laboratory, Delft University of Technology, Delft, 1978.

[8] Contiero ID. Confronto sperimentale di elementi strutturali in calcestruzzo normale e ad alta resistenza in fase fessurata. Degree Thesis, Department of Construction and Transportation, University of Padova, 1997 [in Italian].

[9] Kani GNJ. Basic facts concerning the shear failure. ACI J 1966;64(6):675-92.

[10] Cervera M, Barbat AH, Hanganu A, Oñate E. Evaluación de la presión de fallo del edificio de contención de una central nuclear tipo PWR-W, tres lazos. Parte I: metodologiá. Revista International de Métodos Numéricos para Cálculo y Diseño en Ingeniería 1995;11(2):271-93.

[11] Cervera M, Barbat AH, Hanganu A, Oñate E. Evaluación de la presión de fallo del edificio de contención de una central nuclear tipo PWR-W, tres lazos. Parte II: simulación numérica. Revista International de Métodos Numéricos para Cálculo y Diseño en Ingeniería 1995; 11(3):451-75.

[12] Hanganu A, Oller S, Onate E, Barbat AH. A finite element model for damage analysis of nuclear reactor containment shells. Int Conf on Boundary and finite Elements May 1315, Sibiu, Romania, 1993.

[13] Hanganu A, Barbat AH, Oller S, Oñate E. Simulación del daño sismico en edificio de hormigón armado. Monografia CIMNE IS-4, Barcelona, Spain, 1994.
[14] Barbat AH, Oller S, Oñate E, Hanganu A. In: Alder H, et al. editors. Simulation of damage phenomena in reinforced concrete buildings subjected to seismic actions. Int Congress on Numerical Methods in Engineering and Applied Sciences, CIMNE, Barcelona, 1992.

[15] Oñate E. Reliability analysis of concrete structures. Numerical and experimental studies. Seminar CIAS (Centro Internazionale di Aggiornamento Sperimentale e Scientifico) Evoluzione nella sperimentazione per le costruzioni. Merano, Italy, 1994. p. 125-46.

[16] Giaccio G, Rocco C, Zerbino R. The fracture energy of high strength concretes. Mater Struct RILEM 1993; 26:381-6.

[17] Pijaudier-Cabot G, Bažant ZP. Nonlocal damage theory. J Engng Mech ASCE 1987;113:1512-33.

[18] Schreyer H, Chen Z. One dimensional softening with localisation. J Appl Mech ASME 1986;53:791-7.

[19] Bazant ZP. Why continuum damage is non local: justification by a quasi-periodic microcrack array. Mech Res Comm 1987;14:407-19.

[20] Pijaudier-Cabot G, Benallal A. Strain localisation and bifurcation in nonlocal continuum. Int $\mathbf{J}$ Solids Struct 1993;30:1761-75.

[21] Bažant ZP, Pijaudier-Cabot G. Measurement of characteristic length of non local continuum. J Engng Mech ASCE 1989;115(4):755-67.

[22] Oliver J. A consistent characteristic length for smeared cracked models. Int J Numer Meth Engng 1989;28:471-4.

[23] Bazant ZP, Oh B. Crack band theory for fracture of concrete. RILEM Mater Struct 1983;16:155-77.

[24] William KJ. Experimental and computational aspects of concrete fracture. In: Damjanic F, et al. editors. Proc Int Conf Computer Aided Analysis and Design of Concrete Structures. Swansea: Pineridge Press; 1984. p. 33-70.

[25] Rots JG. Computational modeling of concrete fracture PhD Dissertation, Delft University of Technology, Delft, 1988.

[26] Mang HA, Hofsetter G. Computational Mechanics of Reinforced Concrete Structures. Vieweg Verlag, Braunschweig, Wiesbaden; 1995.

[27] Dubè J-F, Pijaudier-Cabot G, La Borderie C. Rate dependent damage model for concrete in dynamics. Int $\mathbf{J}$ Engng Mech ASCE 1996;122(10):939-47.

[28] Farja R, Oliver J. A strain-based viscous-plastic-damage model for massive concrete structures. Int J Solids Struct 1998;35(14):1533-58.

[29] Saetta A, Scotta R, Vitaliani R. In: Oñate E, Idelsohn SR. editors. Seismic analysis of reinforced concrete frames with a scalar damage model in Computational Mechanics, New Trends and Applications, CIMNE. Barcelona, Spain, 1998.

[30] Horvat R, Persson R. The influence of specimen size on the fracture energy of concrete. Report TVBM-5005, Lund Institute of Technology, Lund, Sweden, 1984.

[31] ACI-ASCE Committee 426. The shear strength of reinforced concrete members. Proc ASCE J Struct Div 1973;99 [Chapters 1-4].

[32] Cervera M, Hinton E. Non-linear analysis of reinforced plates and shells using a three dimensional model. Computational Modelling of reinforced concrete Structures. Swansea: Pineridge Press; 1986. 
[33] Cervera M, Hinton E, Bicanic N. Non-linear transient dynamic analysis of three dimensional model. Numerical Methods in Transient and Coupled Analysis London: Wiley; 1987.

[34] Cervera M, Hinton E, Bicanic N, Bonet J. Non-linear transient dynamic analysis of three dimensional model - A FEM program for steel and reinforced concrete structures.
Numerical Methods and Software for Dynamic Analysis of Plates and Shells Swansea: Pineridge Press; 1988.

[35] Park R, Paulay T. Reinforced concrete structures, London: Wiley; 1974.

[36] Pamin J, de Borst R. Simulation of crack spacing using a reinforced concrete model with an internal length parameter. Arch Appl Mech 1998;68(9):613-25. 